\title{
PREDICTORS OF SUCCESS FOR ADULTS WITH TYPE 1 DIABETES ON CONTINUOUS SUBCUTANEOUS INSULIN INFUSION THERAPY: A RETROSPECTIVE REVIEW
}

\author{
A Thesis \\ Presented in Partial Fulfillment of the Requirements for \\ the Degree Master of Science in the Graduate \\ School of The Ohio State University
}

By

Mary Kathryn Ausich, B.S.

Graduate Program in Allied Medical Professions

The Ohio State University

2010

Master's Examination Committee:

Dr. Maureen E Geraghty, Adviser

Dr. Marcia Nahikian-Nelms

Janet Zappe 



\begin{abstract}
Background/ Objective: Complications can ensue from uncontrolled type 1 diabetes, resulting in compromised quality and duration of life, and increased health care costs. The provision of insulin is achieved by multiple daily injections (MDI) or by insulin pump through continuous subcutaneous insulin infusion (CSII). The primary objective was to determine the difference between hemoglobin $\mathrm{A}_{1 \mathrm{c}}\left(\mathrm{HbA}_{1 \mathrm{c}}\right)$ before and after the switch from MDI to CSII therapy.
\end{abstract}

Methods: In this retrospective medical record review, paired t-tests were used for all of the pre-post comparisons. To determine whether external factors were related to a successful reduction in $\mathrm{HbA}_{1 \mathrm{c}}$ after pump initiation, the pre-post $\mathrm{HbA}_{1 \mathrm{c}}$ difference was used as the outcome in a linear regression model, and potential patient characteristic covariates were evaluated univariately for their predictive ability: age, gender, duration of diabetes, age at diagnosis, average insulin pre-pump units (absolute and per kg body weight), weight, insulin and pump types, and the presence of various complications. Of the 107 subjects initially identified, 42 subjects met inclusion criteria.

Results: The average $\mathrm{HbA}_{1 \mathrm{c}}$ of participants decreased by $0.55 \%$ from pre-pump values (P $=0.0001)$, the average daily insulin dose per kilogram of body weight decreased by 0.061 
$\mathrm{U} / \mathrm{kg},(\mathrm{P}=0.0029)$, and weight decreased by $0.07 \mathrm{~kg}$. ( $\mathrm{P}=0.86)$. None of the continuous or categorical variables were found to be statistically significant at predicting a pre- to post-reduction in $\mathrm{HbA}_{1 \mathrm{c}}$ levels.

Conclusions: This study suggests that all study participants, regardless of patient characteristics, benefited from the transition from MDI to CSII therapy. 


\section{ACKNOWLEDGEMENTS}

I would like to thank my adviser, Dr. Maureen Geraghty, for her support, time, and encouragement throughout the last three years. This thesis would not have been possible without her continued guidance and words of wisdom. I would also like to thank

Janet Zappe for her assistance with data collection as well as her generous contribution of time and effort over the last year. In addition, I would like to extend my gratitude to Gregory Young for his interest and commitment in helping to develop the statistics for this study and Dr. Christopher Taylor for his last minute assistance with formatting. I would also like to thank Dr. Marcia Nahikian-Nelms for her careful reading to improve the final manuscript and my mom for her assistance with editing. Finally, I would like to thank my family for their unwavering love and support throughout the last three years. Their words of encouragement and confidence, as well as their unending ability to provide a voice of reason and a listening ear, were greatly appreciated. 
VITA

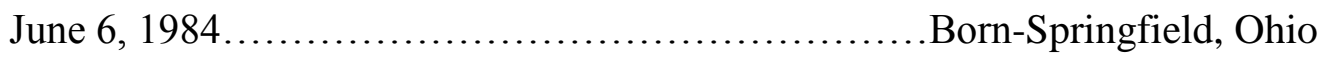

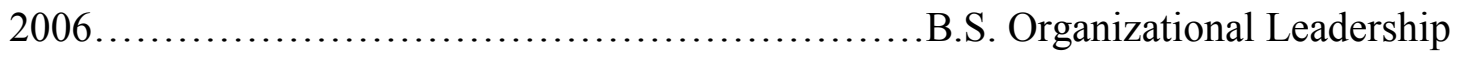
Management, Miami University

2007-2010

Coordinated Master's Program

The Ohio State University

\section{FIELD OF STUDY}

Major Field: Allied Medical Professions

Medical Dietetics 
4. Predictors of Success for Adults with Type 1 Diabetes on Continuous Subcutaneous Insulin Infusion: A Retrospective Review..................................32

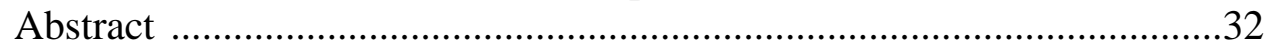

Introduction and Statement of Purpose .................................................33

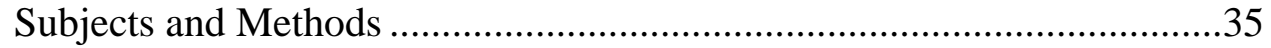

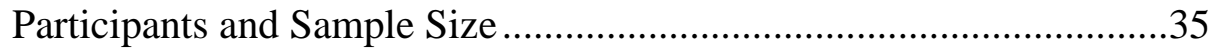

Insulin Pump Clinic Program............................................................35

Data Collection at the Insulin Pump Clinic ........................................38

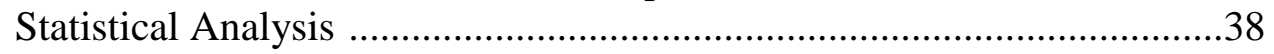

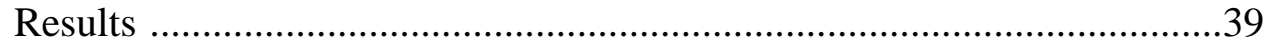

Patient Flow and Baseline Characteristics ........................................39

$\mathrm{HbA}_{1 \mathrm{c}}$, Insulin Dose Change, and Weight Change ............................40

Continuous and Categorical Predictors of Success .............................43

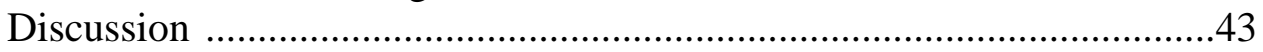

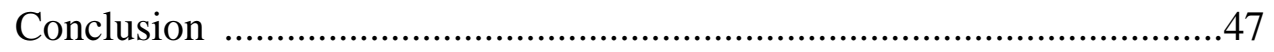

5. Summary and Conclusions .......................................................................49

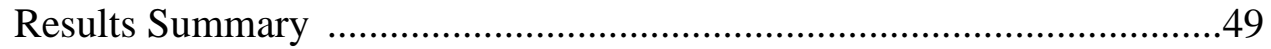

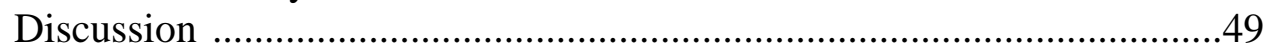

Limitations and Implications for Further Research .............................51

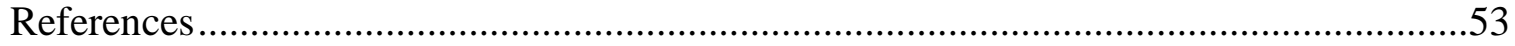

Appendices

Appendix A-IRB Approval .............................................................56

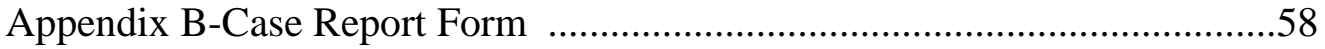

Appendix C-Tables .....................................................................60 


\section{LIST OF TABLES}

Table $\quad$ Page

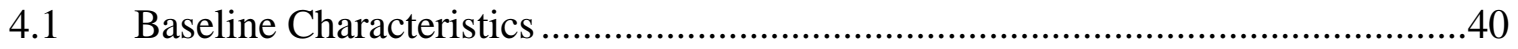

A.1 Univariate Analysis of Continuous Predictors.............................................60

A.2 Univariate Analysis of Categorical Predictors..............................................61 


\section{LIST OF FIGURES}

FIGURE $\quad$ Page

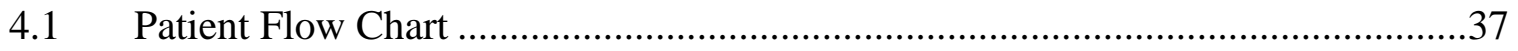

$4.2 \quad \mathrm{HbA}_{1 \mathrm{c}}$ Pre-and Post-Pump Initiation....................................................... 41

4.3 Insulin Units Pre- and Post-Pump Initiation ..................................................42

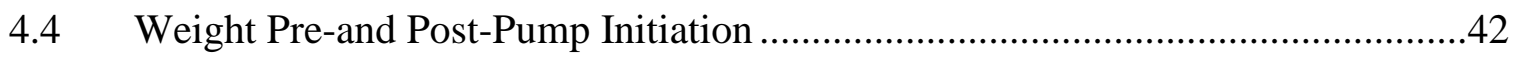




\section{CHAPTER 1}

\section{INTRODUCTION}

\section{Background and Significance of the Problem}

Diabetes has become a serious health problem in the United States over the last several decades, and the number of Americans inflicted with diabetes is continually rising. It is estimated that eight percent of the population, or about 23.6 million adults and children in the United States, have some form of diabetes [1]. Because the incidence rate of diabetes is increasing, diabetic complications are also on the rise. Several serious diabetic complications can arise from long-standing diabetes, especially when diabetics exhibit poor glycemic control. These complications include cardiovascular disease, hypertension, and dyslipidemia as well as microvascular complications such as neuropathy, nephropathy, and retinopathy. Diabetic complications can decrease quality of life, increase health care costs, and result in a shortened life for an individual with diabetes. However, in the Diabetes Control and Complications Trial [2], good glycemic control, achieved through intensive diabetes management, resulted in a lowered incidence of microvascular diabetic complications. After the results of this landmark study were released, it has become even more crucial to determine which methods of diabetic management result in the most success for optimal glycemic control. 
Two intensive diabetes management therapies are available, multiple daily injections (MDI) and continuous subcutaneous insulin infusion (CSII), also known as insulin pump therapy. Although both methods are widely used, it is unclear which treatment option is superior in terms of achieving optimal glycemic control. Because both treatment options have distinct advantages and disadvantages, working with patients individually and determining the best treatment option may be most effective when considered on a case by case basis. The development of criteria as to when each treatment option is indicated may assist health care providers when determining a treatment option. Because diabetes has become such a prevalent disease in our country, it is imperative that the best treatments are employed to help control the long-term effects of diabetes, optimize glycemic control, and improve the overall quality of life for diabetics.

\section{Objectives}

The four primary objectives of this study were the following:

1. To evaluate whether blood glucose control, as measured by hemoglobin $\mathrm{A}_{1 \mathrm{c}}$, improves in patients with type 1 diabetes when they switch from multiple daily injections to insulin pump therapy

2. To determine whether total daily insulin requirement per kilogram of body weight increases or decreases in patients with type 1 diabetes when they switch from multiple daily injections to insulin pump therapy

3. To describe the correlations between weight changes, hemoglobin $A_{1 c}$, and insulin requirements in patients with type 1 diabetes when they switch from multiple daily injections to insulin pump therapy 
4. To identify which patient characteristics (age, gender, duration of diabetes, age at diagnosis, average insulin pre-pump (raw units and per $\mathrm{kg}$ of body weight), weight, type of insulin used, pump type, and the presence of various complications) may be predictive of success on an insulin pump

\section{Research Questions}

This study sought to discover what factors lead to success or inhibit success when type 1 diabetic patients switch from multiple daily injections to insulin pump therapy. The questions answered were the following:

1. Are patients on multiple daily injections more or less successful after switching to continuous subcutaneous insulin infusion as measured by hemoglobin $\mathrm{A}_{1 \mathrm{c}}$, insulin dose change, and weight change?

2. Can it be predicted, based on patient characteristics, which patients will be most successful on an insulin pump?

\section{Research Approach}

This study was a retrospective medical record review. Patients who completed the switch from MDI to CSII therapy under the guidance of The Ohio State University Division of Endocrinology, Diabetes, \& Metabolism Insulin Pump Clinic in Columbus, Ohio between May 2005 and August 2009 were analyzed in this study if they met inclusion criteria. 


\section{Glossary of Terms}

Casual Plasma Glucose: A blood glucose measurement obtained without regard to when the last meal was consumed

Dawn Phenomenon: A natural increase in blood glucose levels observed in the morning hours in individuals with diabetes

Dyslipidemia: An abnormality in any of the blood lipoproteins; increases the risk for the development of heart disease [3]

Fasting Plasma Glucose: Blood glucose level obtained after a minimum eight hour fast Hemoglobin $\mathbf{A}_{1 \mathrm{c}}$ : A measure of an individual's average blood glucose over the previous two to three months, measured in $\mathrm{mg} / \mathrm{dL}$

Hyperglycemia: Excessive glucose in the blood, generally over $180 \mathrm{mg} / \mathrm{dL}$ [3]

Hypoglycemia: Low blood glucose level, generally less than $70 \mathrm{mg} / \mathrm{dL}$ [3]

Hypertension: Blood pressure exceeding 140/90 mm/Hg [3]

Intensive Diabetes Management: Diabetes management through either multiple daily injections or continuous subcutaneous insulin infusion

Nephropathy: Dysfunction of the kidney leading to microalbuminuria and eventually end-stage liver disease

Neuropathy: Nerve damage

Oral Glucose Tolerance Test: Administration of a 75 gram glucose load followed by blood sugar checks at specified intervals

Polydipsia: Excessive thirst

Polyphagia: Excessive hunger

Polyuria: Excessive urination 
Retinopathy: Occurs when blood vessels of the retinal leak and produce spotty hemorrhages, resulting in decreased vision and eventually blindness if not treated [3]

Type 1 Diabetes: Insulin-dependent diabetes; generally occurs in persons under the age of thirty but can be diagnosed at any age.

Type 2 Diabetes: Noninsulin-dependent diabetes; generally occurs in persons over the age of thirty, but can be diagnosed in younger individuals 


\section{CHAPTER 2}

\section{REVIEW OF LITERATURE}

\section{Background of Diabetes}

Diabetes has become a prevalent health problem in the United States over the last few decades, affecting an estimated 23.6 million adults and children or close to $8 \%$ of the population [1]. Unfortunately, nearly one quarter of those affected with diabetes, or approximately 5.7 million people, are unaware they have the condition [1]. Diabetes, a disease that affects either the production or efficient use of insulin, thereby resulting in the body's inability to process glucose, has two major forms. Type 1 diabetes, the less prevalent form, is typically diagnosed in children and adolescents, although individuals of any age can be diagnosed. It occurs when the pancreas ceases production of insulin due to the destruction of pancreatic beta cells that produce insulin, making the body's cells unable to utilize glucose [4]. This results in hyperglycemia. At the time of diagnosis, patients typically present with polyuria, polydipsia, polyphagia, and excessive weight loss [3]. For patients with type 1 diabetes, daily injections of exogenous insulin is required for survival. It is estimated that only five to ten percent of Americans diagnosed with diabetes will be diagnosed with type 1 diabetes $[1,3]$. Type 2 diabetes, the most 
common form, can affect individuals of any age but is primarily found in adults. This type of diabetes occurs when the body becomes resistant to the insulin produced by the pancreas, resulting in less effective use of the hormone [1]. Often, type 2 diabetics have high levels of insulin in their bodies, as the pancreas attempts to compensate for inadequate insulin uptake by cells by producing additional insulin. Unlike type 1 diabetes, which usually has a sudden onset, type 2 diabetes often has a very slow progression as hyperglycemia develops slowly, and the classic symptoms of diabetes may not be present [3]. Because of this, type 2 diabetics can live with the condition for several years before it is diagnosed, increasing the likelihood that diabetic complications will arise in the future.

Three methods can be used to diagnose diabetes. These three methods include fasting plasma glucose, casual plasma glucose, and testing an individual's two-hour plasma glucose level. Fasting plasma glucose is obtained after fasting has occurred for a minimum of eight hours. A normal fasting plasma glucose is less than $100 \mathrm{mg} / \mathrm{dL}$ and a value greater than or equal to $126 \mathrm{mg} / \mathrm{dL}$ can be an indicator that an individual has diabetes [3]. A casual plasma glucose is a glucose value that is obtained at any time of the day, without consideration of when the last meal was consumed. If a casual plasma glucose value is above $200 \mathrm{mg} / \mathrm{dL}$ and the individual displays classic symptoms of diabetes, such as polydipsia, polyuria, polyphagia, and weight loss, diabetes can be diagnosed [3]. In the third method, the two-hour plasma glucose level is measured when an oral glucose tolerance test is administered. An oral glucose tolerance test is administered after fasting, and 75 grams of glucose are given. Two hours after the glucose is consumed, an individual's blood glucose value is measured [1,3]. A normal 
two-hour plasma level is less than $140 \mathrm{mg} / \mathrm{dL}$, and a value of $200 \mathrm{mg} / \mathrm{dL}$ or greater indicates diabetes [3]. If one of the above tests is administered and clear hyperglycemia is not indicated, the diagnoses must be confirmed with a subsequent test, using any of the three diagnostic methods [3].

\section{Diabetic Complications}

As a result of high blood glucose, especially long-standing hyperglycemia, individuals with diabetes are susceptible to a wide array of complications. The complications associated with diabetes fit into two broad categories, macrovascular diseases and microvascular diseases, which includes neuropathy. Macrovascular complications include heart disease, hypertension, and dyslipidemia [3]. It is estimated that heart disease is responsible for $65 \%$ of the deaths of diabetic individuals [1]. In addition, individuals with diabetes are more likely to develop heart disease at an earlier age, and the condition is often more severe in diabetics than in nondiabetics [3]. Hypertension is a common co-morbidity seen in individuals with diabetes; an estimated $73 \%$ of adults with diabetes have blood pressure greater than $130 / 80 \mathrm{~mm} \mathrm{Hg}$ or are taking prescription medications to lower blood pressure $[1,3]$. Because hypertension can lead to further macro- and microvascular conditions, it should be treated aggressively in patients with diabetes, including lifestyle changes and blood pressure lowering medications [3]. Lipid abnormalities such as high cholesterol and triglyceride levels, also known as dyslipidemia, are more prevalent in diabetics as opposed to nondiabetic individuals and should be treated aggressively [3]. Improvement in dyslipidemia may be achieved through lifestyle modifications but, if unsuccessful, lipid-lowering medications may be indicated. 
Microvascular diseases affect the small blood vessels in the body and include nephropathy, retinopathy, and neuropathy. Diabetic nephropathy, also known as kidney disease, is a serious complication that can arise from uncontrolled high blood glucose values. Diabetes is the leading cause of kidney failure and accounted for $44 \%$ of new cases of end-stage renal disease (ESRD) in 2005 [1]. When ESRD develops, chronic dialysis or a kidney transplant becomes necessary. Diabetic retinopathy, an eye condition that affects the retina, is the most frequent cause of blindness in adults between the ages of 20 and $74[1,3]$. Nearly all patients with type 1 diabetes will have some degree of diabetic retinopathy after living with diabetes for 20 years [3]. However, if type 1 diabetic patients are able to keep blood glucose values as close to normal as possible for an extended period of time, they can reduce retinopathy damage to their eyes by as much as $76 \%[1,2]$. Finally, neuropathy, or nerve damage, is also a common complication seen in diabetic patients. It is estimated that between $60 \%$ and $70 \%$ of all patients with diabetes experience some degree of neuropathy $[1,3]$. As a result of neuropathy, patients can experience decreased sensation in extremities such as the hands and feet and slowed gastric emptying [1]. If lower extremity neuropathy is severe enough, amputation of a lower extremity may become necessary [1]. Although many life-altering complications can arise from diabetes, these complications can be delayed or eliminated if good blood glucose control is maintained.

\section{Chronological Treatment of Diabetes through the Years}

Prior to the discovery and isolation of insulin, diabetic patients, especially type 1

diabetics, had an extremely grim outlook. A patient diagnosed with diabetes could expect a shortened life, often enduring extreme diets and many infections and complications [4, 
5].The discovery and first extraction of insulin in 1921 by scientists Fredrick G. Banting, Charles H. Best, James B. Collip, and J.J.R. MacLeod began a new era in the treatment of diabetes $[4,6]$. Prior to this time, many extreme treatments were attempted, including the use of opium, exceptional personal hygiene, and extreme starvation diets; however, none of these treatments proved to provide effective diabetes management and extend the lives of those inflicted with the condition [6].

It is generally accepted that Canadian scientists Banting, Best, Collip, and MacLeod were the individuals responsible for the discovery of insulin at the University of Toronto, even though only Banting and MacLeod received the Nobel Prize for their work. It is believed that in 1921, Banting, Best, Collip, and MacLeod extracted insulin from the islets of animal pancreases, which allowed the use of insulin to lower blood glucose levels for the first time [4]. Nearly a year later, in 1922, bovine insulin was injected for the first time into a diabetic patient, Leonard Thompson $[4,5]$. Because early insulin was extremely impure, the injection resulted in a severe local reaction at the insertion site, but it also reduced the blood sugar level of the patient, and the patient experienced improved health [4, 5]. In February of 1922, following the successful administration of bovine insulin to Thompson, six additional diabetic patients were treated with insulin [5]. Following these successful treatments, the demand for insulin quickly escalated, and multiple companies, including Connaught Laboratories of the University of Toronto and Eli Lilly in Indianapolis, were granted licenses to begin production of insulin $[4,5]$.

In 1936, the first slow-acting insulin was produced when protamine, a low-weight protein, was combined with zinc to produce Protamine zinc insulin (PZI). The effect of 
this new insulin lasted between 24 and 36 hours [4].This development was followed by several advances in the 1950's that improved the treatment of diabetes. In 1950, neutral protamine Hagedorn (NPH insulin) became available. This insulin was also bound to protamine, had an effect for a maximum of 24 hours, and could be mixed with fast-acting insulin [4]. In 1951 'lente' insulins (IZS) were developed. These insulins, which include semilente, lente, and ultralente, allowed many diabetic patients to achieve control with a single morning dose or a split dose-one in the morning and one in the evening [4]. Finally, in 1956, the first oral drugs for the treatment of type 2 diabetes were available. In 1974, treatment of diabetic patients improved further when new techniques allowed for the production of highly purified animal insulin [4]. Prior to the chromatographic purification technique, animal insulins caused antibody allergies and lipoatrophy in some patients [4]. Even though animal insulin greatly improved with purification, recombinant 'human' insulin and analogues, developed in the 1960's, would soon become the insulin of choice for most physicians and their diabetic patients [4]. In 1975, a fully synthetic insulin was developed in Basel, and when tested on six diabetic patients, it was noted that although the new synthetic insulin did cause more sudden hypoglycemic events in two patients, the insulin was overall well tolerated [4]. In 1978, the Genetech Corporation in San Francisco successfully manipulated E. coli to produce an insulin that had an identical amino sequence as the insulin seen in humans [4]. It was in 1980 that recombinant DNA or 'human' insulin was first tested on diabetic patients in England. It was concluded that 'human' insulin was a successful treatment, but the insulin may have had a different potency level than porcine insulin, which had been used to this point [4]. With the seventeen patients on which that the new 'human' insulin was 
tested, it was believed that 'human' insulin was more potent than porcine insulin when given in a low dose and less potent than porcine insulin when given at a higher dose [4]. With successful trials of 'human' insulin complete, many companies quickly tried to mass produce this new insulin for release to a broader market. In 1982, Eli Lilly was the first company that produced 'human' insulin in the United States market, with their Humulin R (rapid acting insulin) and Humulin N (NPH insulin) being granted FDA approval [4]. Other companies quickly followed, and many different 'human' insulins quickly became available. Since 1996, several different insulin analogues have come to the market, including Lantus, Levemir, and NovoRapid. In addition, large number of insulin analogues are still being tested, and new options for the treatment of diabetic patients will likely continue to be available [4].

Although 'human' insulin and analogues have become the treatment option for diabetics requiring insulin in the United States, some individuals still argue that porcine and bovine animal insulin should continue to be considered as viable treatment options. Those who argue this point contend that 'human' insulin causes more hypoglycemic events with fewer symptoms, which can be extremely dangerous for diabetic patients [4]. On the other hand, animal insulin, although able to provide successful treatment for diabetic patients, does not have identical amino acid bonds as human insulin, which can cause an allergic reaction or resistance to the insulin $[4,5]$. With continued development of 'human' insulin and analogues in the United States, as well as the successful treatment of diabetic patients with these types of insulin, it seems unlikely that animal insulin will again become the prevalent treatment form in the United States. 


\section{Diabetes Control and Complications Trial}

The Diabetes Control and Complications Trial [2] was a major clinical trial conducted between 1983 and 1993. The study was a randomized, controlled multicenter trial that compared two treatment options for diabetics to determine their effect on longterm complications. The two treatments being compared were conventional therapy and intensive therapy. Conventional therapy consisted of one or two daily insulin injections and blood glucose monitoring, as well as diet and exercise education. In addition, those on conventional therapy did not make daily adjustments to their insulin dose based on blood glucose values. Individuals receiving intensive therapy could choose between multiple daily injection therapy or pump therapy. Individuals on intensive therapy received insulin three or more times per day and monitored their blood glucose level a minimum of four times per day. Insulin dosage was adjusted regularly based on blood glucose and dietary logs as well as on anticipated physical activity. Patients in the intensive therapy had a monthly in-person meeting with a clinician to make adjustments to insulin dosage as well as phone contact with the clinician on a more frequent basis.

In 1993, when the study was terminated, patients had an average follow-up of six and one half years [2]. The results of this study clearly indicated that intensive therapy was superior to conventional therapy in reducing long-term complications for diabetic patients. Retinopathy, a common complication seen in diabetic patients, was reduced by $76 \%$ in patients in the intensive as compared to conventional therapy treatment group at the end of the study. In addition, microalbuminuria and albuminuria, early signs of diabetic kidney disease, were also significantly reduced in the intensive therapy group as compared to the conventional therapy group. Similar results were seen for neuropathy, as 
those in the intensive therapy group had significantly lower incidence and progression than those in the conventional therapy group. Overall, the results of the Diabetes Control and Complications Trial clearly indicated that intensive therapy through either multiple daily injections or an external insulin pump, significantly reduce diabetic complications and allow diabetic individuals to lead a healthier life.

\section{Intensive Diabetes Management: Multiple Daily Injections vs. Insulin Pump Therapy}

The Diabetes Control and Complications Trial significantly underscored the importance of intensive diabetes management in reducing the risk of diabetes related complications. The primary goal of intensive diabetes management is for the patient to achieve near-normal glycemia and avoid severe hypoglycemic events [7, 8]. For a patient to achieve success with intensive diabetes management, he or she must receive continuing patient education and motivation and psychological support by certified health care professionals [8]. It is also necessary for patients to complete thorough blood glucose and food logs to enable educated decisions regarding insulin dose changes, to become proficient in carbohydrate counting, and to monitor blood glucose levels a minimum of four times per day. By following an intensive diabetes management program, patients see several advantages in addition to the reduction in long-term complications. Patients are able to have greater control over the management of their condition, have more flexibility in the timing of meals, and insulin doses can be altered to accommodate exercise or varying carbohydrate intake [7]. In addition, intensive diabetes management can reduce the risk of complications during pregnancy [7]. Although initiating intensive diabetes management in newly diagnosed type 1 diabetics is 
encouraged because of the multitude of benefits, intensive diabetes management may not be an appropriate treatment option for all individuals, due to increased financial costs and the patient dedication required for success [7].

Multiple daily injections (MDI) is the first intensive diabetes management treatment option. With this treatment, patients receive one to two injections of longacting insulin per day as well as injections of short-acting insulin with each meal based on the amount of carbohydrate consumed. Patients also use a correction factor to administer extra short-acting insulin based on a pre-determined ratio if blood glucose levels are high. The long-acting insulin keeps the patient's baseline blood glucose level within an acceptable range, and the short-acting insulin accommodates the carbohydrates in each meal. Insulin pump therapy, also known as continuous subcutaneous insulin injection (CSII) therapy is the second intensive diabetes management treatment option. With this treatment, patients wear an external pump which delivers short-acting insulin to the patient consistently, based on pre-programmed insulin delivery rates set by the patient and health care provider. When food is consumed, the patient inputs his or her blood glucose value and the amount of carbohydrates consumed, and a bolus insulin dose is given to accommodate the food consumed and any correction factor needed to adjust based on the patient's current blood glucose level.

Although each treatment option can be very effective and help the patient achieve near-normal blood glucose control, it has been debated which treatment option is most ideal for patients. Both MDI and CSII have benefits and drawbacks, and they must be considered carefully when patients and health care providers are choosing the best treatment option. MDI has several advantages over CSII. MDI is less expensive and 
requires less self-management by the patient, often resulting in an easier to follow regimen [9]. In addition, MDI presents little or no risk for equipment malfunction, such as an insulin delivery occlusion, which could result in hyperglycemia. Although MDI does require patient education, the education is usually not as intense as that required for CSII. Although many advantages exist for MDI, there are also many disadvantages. First, MDI requires patients to take a minimum of three injections, often more, which is unappealing to many patients [8]. In addition, MDI uses both long- and short-acting insulin while CSII uses only short-acting insulin. It has been shown that the absorption rate can vary by as much as $52 \%$ in long-acting insulin, causing unexplained hypo- or hyperglycemic events [8]. On the other hand, short-acting insulins' absorption rate is thought to vary by only about 3\% [8]. A final disadvantage is that the basal insulin dose cannot be readily altered to accommodate for exercise.

CSII, the second intensive diabetes management treatment option also has several advantages and disadvantages. The first advantage is that CSII reduces the risk for nocturnal hypoglycemia, dawn phenomenon, and exercise-induced hypoglycemia because the insulin pump allows the user to program different basal rates at different times of the day and set temporary basal rates to make accommodations for exercise [8]. Reducing dawn phenomenon, a natural increase in blood glucose levels and insulin requirements in diabetics in the morning hours, is favorable and can help to achieve optimal glycemic control. A second advantage is the ability for patients to utilize several different bolus options, including the normal bolus as well as specialty boluses, which can provide better mealtime coverage for certain foods. Finally, CSII can simulate the normal function of the pancreas more effectively than MDI, which helps mimic the 
normal fluctuations seen in blood glucose values of nondiabetic individuals $[8,10]$. CSII also has several disadvantages. First, CSII can inflict a greater psychological burden on patients than MDI [11]. In addition, CSII has a higher cost, and patients endure more time consuming self-care demands [9]. CSII also presents many unique challenges, including pump malfunction, which can lead to hyperglycemia, infections at the infusion site, and irritation or discomfort caused by the infusion set $[7,10]$. Finally, there may be some characteristics that people exhibit that may contraindicate the use of the pump. Preexisting psychological disorders, alcohol or drug abuse, and the inability to maintain the self-care necessary for success on an insulin pump may all indicate that a patient is not a good candidate for pump therapy [12].

Although it is well- documented that intensive diabetes management is the optimal treatment method for diabetic patients, the best type of therapy is still debated. Because both MDI and CSII have distinct advantages and disadvantages, it is likely wise to closely consider each patient's commitment and ability level when determining an appropriate treatment regimen.

\section{Outcome Measures: Hemoglobin A1c, Total Daily Insulin Dose, and Weight}

\section{Change}

Hemoglobin A1c, total daily insulin dose, and weight change are all important measures to determine patient success on a diabetic therapy. As patients transition from MDI to CSII, measuring these three outcome measures will provide some basis to determine relative success on each treatment. Hemoglobin $\mathrm{A}_{1 \mathrm{c}}\left(\mathrm{HbA}_{1 \mathrm{c}}\right)$, also referred to as glycosated hemoglobin, is a widely used measure to assess blood glucose control over the previous two to three months. When the body has an excessive amount of glucose, the 
excess glucose attaches to red blood cells and produces glycosated hemoglobin. The more glycosated hemoglobin in the body, the higher the $\mathrm{HbA}_{1 \mathrm{c}}$ will be. A normal $\mathrm{HbA}_{1 \mathrm{c}}$ for a nondiabetic individual is between $4.0 \%$ and 6.0\%. The American Diabetes Association recommends an $\mathrm{HbA}_{1 \mathrm{c}}$ value of less than $7.0 \%$, although many health care professionals push for an as near-normal level as possible, often recommending below either $6.5 \%$ or $6.0 \%$ [7]. It is well documented that intensive diabetes management is superior to conventional diabetes treatment at reducing long-term diabetic complications, as it is easier to maintain near-normal blood glucose values with intensive diabetes management.

Total daily insulin dose, measured in units/kg of body weight, is also an important measure. The goal for patients with diabetes is to achieve optimal glycemic control on as little insulin as possible. This provides the best care and helps to prevent weight gain, which can be a result of an increased insulin dose. In turn, weight change is an important outcome measure when observing treatment change from MDI to CSII. Avoiding excessive weight gain is optimal with any diabetes therapy.

\section{Recent Studies Comparing Multiple Daily Injections and Continuous Subcutaneous Insulin Infusions}

Many studies have been conducted to determine if multiple daily injections or continuous subcutaneous insulin infusions, both intensive diabetes management treatments, provide a more successful means for patients to achieve near-normal blood glucose values. Although studies have been conducted since the 1980's, more recent studies give a better indication of the comparison between MDI and CSII because insulin pump therapy has greatly advanced over the last several years. 
In a randomized crossover open-label design, Hanaire-Broutin et al [13] compared the efficacy on glycemic control between CSII and MDI with insulin lispro. Forty type 1 diabetic patients were included in the study and were randomly assigned to receive either CSII with lispro or MDI for the first four months of the trial. MDI consisted of three injections of lispro per day (an injection before each meal) and two injections of NPH per day, one before breakfast and one at bedtime. After the initial four month period, subjects were switched to the opposite treatment group and completed a second four month period. Throughout the study, no significant differences were observed in weight. While subjects were receiving CSII, mean weight was $68.7 \mathrm{~kg} \pm 10.0$ $\mathrm{kg}$ and mean weight during MDI was $69.0 \mathrm{~kg} \pm 9.5 \mathrm{~kg}$. At baseline, mean insulin dose for the participants was $43.6 \pm 13.5$ units/day. Total insulin dose required to maintain glucose control during CSII was significantly lower than the total insulin dose required during MDI (38.5 \pm 9.8 units/day during CSII; $47.3 \pm 14.9$ units/day during MDI). $\mathrm{HbA}_{1 \mathrm{c}}$ was measured at the end of each period. They found that the average $\mathrm{HbA}_{1 \mathrm{c}}$ at the end of each period of treatment was $7.89 \% \pm 0.77 \%$ with CSII and $8.24 \% \pm 0.77 \%$ with MDI. It was determined that $\mathrm{HbA}_{1 \mathrm{c}}$ was significantly lower with CSII treatment as compared to MDI ( $\mathrm{P}<0.001)$. It was concluded that when using insulin lispro, insulin pump therapy provides better glycemic control than MDI therapy.

In a cross-sectional study, Hoogma et al [11] compared metabolic control and quality of life in type 1 diabetic patients who had been stable on either CSII or MDI therapy for an extended period of time (at least one year). Patients were asked to complete a questionnaire and the questionnaire, along with the patient's most recent $\mathrm{HbA}_{1 \mathrm{c}}$ value, were returned to the researchers. After compiling the information, it was 
determined that the difference in $\mathrm{HbA}_{1 \mathrm{c}}$ between the two groups was not significant. The $\mathrm{HbA}_{1 \mathrm{c}}$ for the MDI group was $8.5 \% \pm 1.4 \%$, and the $\mathrm{HbA}_{1 \mathrm{c}}$ for the CSII group was $8.1 \%$ $\pm 1.5 \%$.

In a randomized trial, DeVries et al [14] compared the efficacy in improving glycemic control and quality of life (in relation to health) in type 1 diabetic patients with long-standing poor glycemic control with the primary outcome being change in $\mathrm{HbA}_{1 \mathrm{c}}$. Patients included in the study had experienced persistent poor glycemic control (HbA1c > 8.5\%) while on MDI and for the purpose of the study were randomized to receive either MDI or CSII. The study was originally designed as a crossover study, but due to a high attrition rate after crossover, it was statistically analyzed as a parallel clinical trial. Of the seventy-nine patients randomized, seventy-two patients completed the first phase of the study and were included in analyses. After completion of the study, change in weight was similar in both groups $(0.60 \mathrm{~kg} \pm 2.94 \mathrm{~kg}$ in the CSI group as compared to $0.88 \mathrm{~kg} \pm 2.74$ $\mathrm{kg}$ in the MDI group). It was also observed that insulin requirements decreased in the CSII group but remained stable in the MDI group. Insulin requirement decreased by 15.8 units \pm 15.06 units in the CSII group and increased by 2.9 units \pm 17.01 units in the MDI group. This is a difference of -18.76 units $(\mathrm{P}<0.001)$. The study researchers found that the change in $\mathrm{HbA}_{1 \mathrm{c}}$ in the CSII group was significantly greater as compared to the MDI group: $-0.91 \pm 1.28$ for the CSII group as compared to $-0.07 \pm 0.70 \%$ for the MDII group with $\mathrm{P}=0.002$ and a difference of $0.84 \%(95 \% \mathrm{CI}-1.31$ to -0.36$)$. The study concluded that CSII improved glycemic control in patients with long-standing poor glycemic control. 
To document the long-term efficacy and safety of CSII in comparison with patients previous conventional intensified insulin therapy, Linkeschova et al [15], conducted an observational study of one hundred type 1 diabetic patients. $\mathrm{HbA}_{1 \mathrm{c}}$ was used as a measure to compare metabolic control between patients' previous injection therapy and CSII. As assessed by the questionnaire, weight while using CSII therapy remained stable in 53\% of participants, increased in 22\%, and decreased in $25 \%$ of participants. Although insulin dose was not noted for baseline, at follow-up, the average total daily insulin dosage was 46.8 units/day \pm 15.2 units or about 0.7 units $/ \mathrm{kg}$ of body weight. At the completion of the study, it was found that $\mathrm{HbA}_{1 \mathrm{c}}$ had fallen from $7.7 \%$ $\pm 1.1 \%$ (range $5.3-11.3 \%$ ) at baseline to $7.2 \% \pm 1.0 \%$ (range $5.4-12.7 \% ; \mathrm{P}<0.001$ ) at the time of follow-up. At the time follow-up measures were obtained, patients had been using CSII therapy for a mean of 1.8 years. It was determined that CSII therapy resulted in a significant decrease in $\mathrm{HbA}_{1 \mathrm{c}}$.

In a two year longitudinal, prospective, observational study conducted by Giménez et al, [16] the efficacy of CSII as compared to MDI therapy was compared following the indications and guidelines of the Catalan National Health Service. One hundred thirty-five type 1 diabetic subjects were switched from their previous injection therapy to CSII therapy following the indications for CSII, one of which stated that patients were unable to maintain $\mathrm{HbA}_{1 \mathrm{c}}$ of less than $7.5 \%$ without disabling hypoglycemia. After two years of treatment with CSII, average BMI increased from 24.0 $\pm 3.1 \mathrm{~kg} / \mathrm{m}^{2}$ to $24.4 \pm 3.2 \mathrm{~kg} / \mathrm{m}^{2}(\mathrm{P}<0.025)$. It was also observed that insulin requirements were significantly lower after two years on CSII, $0.55 \pm 0.21$ units $/ \mathrm{kg}$ of body weight after CSII as compared with $0.70 \pm 0.20$ units $/ \mathrm{kg}$ of body weight at baseline. 
In addition, $\mathrm{HbA}_{1 \mathrm{c}}$ decreased from $7.9 \% \pm 1.3 \%$ at baseline to $7.3 \% \pm 1.1 \%(\mathrm{P} \leq 0.001)$. $\mathrm{HbA}_{1 \mathrm{c}}$ was collected at six months and one year in addition to the end point collection at twenty-four months. When compared to baseline $\mathrm{HbA}_{1 \mathrm{c}}$ levels, the reduction in $\mathrm{HbA}_{1 \mathrm{c}}$ was significant at each time point $(6,12$, and 24 months) even though a steady increase in $\mathrm{HbA}_{1 \mathrm{c}}$ was observed after six months when the lowest $\mathrm{HbA}_{1 \mathrm{c}}$ average was recorded (approximately $7.1 \%$ ).

In a retrospective study conducted in an outpatient setting, Karagianni et al [9] compared glycemic control and hypoglycemic episodes in patients with type 1 diabetes using either CSII or MDI therapy. Seventeen patients previously using MDI therapy switched to CSII while seventeen additional subjects remained on MDI therapy. The study did not have randomized selection. In both the MDI group and the CSII group BMI increased slightly from baseline. In the MDI group, BMI increased from $24.6 \pm 0.9$ at baseline to $25.0 \pm 0.9$ at end-point, and in the CSII group, BMI increased from $26.8 \pm 2.8$ at baseline to $27.4 \pm 2.8$ at end-point. In the MDI group insulin requirements remained stable from baseline to the end of the study but insulin requirements decreased from baseline in the CSII group. At baseline, the MDI group averaged 49.4 units/day \pm 4.8 units and at completion of the study averaged 49.6 units/day \pm 4.4 units. In comparison, at baseline the CSII group averaged 49.4 units/day \pm 3.3 units and at completion of the study averaged 39.0 units/day \pm 4.6 units. At baseline the MDI group had an $\mathrm{HbA}_{1 \mathrm{c}}$ of $8.8 \% \pm 0.6 \%$ as compared to the CSII group, which had a baseline $\mathrm{HbA}_{1 \mathrm{c}}$ of $8.4 \% \pm 0.5 \%$. At the end of the study the MDI group had an $\mathrm{HbA}_{1 \mathrm{c}}$ of $7.9 \% \pm 0.4 \%$ as compared to CSII, which had an end point $\mathrm{HbA}_{1 \mathrm{c}}$ of $7.3 \% \pm 0.4 \%$. Although both groups saw a reduction in $\mathrm{HbA}_{1 \mathrm{c}}$ from baseline, only the CSII group had a $\mathrm{p}<0.05$ when comparing 
baseline to end point $\mathrm{HbA}_{1 \mathrm{c}}$ levels. Because the study was nonrandomized, the authors discuss the possibility that the careful selection of patients to transition to CSII from MDI may have cause biased results.

In a long-term randomized trial, Tsui et al [17] evaluated glycemic control and reported on hypoglycemia and quality of life in twenty-seven type 1 diabetic patients who were randomly assigned to receive either MDI or CSII, both using insulin lispro. At completion of the study, the mean total daily dose of insulin did not differ between the the MDI and the CSII groups. The MDI group had a mean of 0.7 units $/ \mathrm{kg}$ of body weight and the CSII group had a mean of 0.6 units $/ \mathrm{kg}$ of body weight for a difference of -0.10 units/kg of body weight $(\mathrm{P}>0.10)$. At baseline, the mean $\mathrm{HbA}_{1 \mathrm{c}}$ for the MDI group was 8.16\%, and the mean $\mathrm{HbA}_{1 \mathrm{c}}$ of the CSII group was $7.73 \%$, which was not a statistically significant difference. At the end of the study, month nine, both groups showed significant decrease in $\mathrm{HbA}_{1 \mathrm{c}}$ from baseline, but there was no clinically significant difference between groups at end point or at any month during the study $\left(\mathrm{HbA}_{1 \mathrm{c}}\right.$ levels were collected monthly for both groups). The mean $\mathrm{HbA}_{1 \mathrm{c}}$ for the MDI group at the end of the study was $7.56 \%$, and the mean $\mathrm{HbA}_{1 \mathrm{c}}$ for the CSII group at the end of the study was 7.38\%. After adjustment for baseline differences, the overall treatment effect (CSIIMDI) was $+0.08 \%$.

In a meta analysis by Retnakaran et al [18] three randomized controlled trials that met inclusion criteria were analyzed to compare CSII and MDI therapy using rapid-acting insulin in type 1 diabetic adults. The meta analysis specifically examined the studies to determine the impact that CSII and MDI therapy have on patients in relation to their baseline $\mathrm{HbA}_{1 \mathrm{c}}$ value. After analysis, the authors determined that the benefit of CSII over 
MDI became more evident in patients who had a higher baseline $\mathrm{HbA}_{1 \mathrm{c}}$ level. For patients with a baseline $\mathrm{HbA}_{1 \mathrm{c}}$ level of $10 \%$, CSII reduced $\mathrm{HbA}_{1 \mathrm{c}}$ by an additional $0.65 \%$ as compared to MDI. If baseline $\mathrm{HbA}_{1 \mathrm{c}}$ was $6.5 \%$ no additional benefit was observed by implementing CSII as compared to MDI.

In a prospective randomized trial by Bolli et al [19], type 1 diabetic adult patients who were previously using NPH injection therapy were randomized to receive either MDI or CSII to assess glycemic control. Fifty patients were included in the analysis, twenty-four patients were receiving CSII therapy and twenty-six patients were receiving MDI therapy, and the patients followed his or her prescribed therapy for six months. At baseline, total daily insulin dose was similar in both groups, 51.0 units/day \pm 15.7 units for the CSII group as compared to 51.2 units/day \pm 16.8 units for the MDI group. At week twenty-four, both groups saw a decrease in total daily dose of insulin, but a larger decrease was seen in the CSII group. At week twenty-four, the CSII groups' mean total daily insulin dose was 36.2 units/day \pm 11.5 units as compared to the MDI group which had a mean total daily insulin dose at twenty-four weeks of 42.6 units/day \pm 15.5 units. $\mathrm{HbA}_{1 \mathrm{c}}$ levels were measured at screening and weeks eight, sixteen, and twenty-four. At completion of the study, it was determined that both groups had similar decreases in their $\mathrm{HbA}_{1 \mathrm{c}}$ values. Subjects in the CSII group had an average reduction in $\mathrm{HbA}_{1 \mathrm{c}}$ of $-0.7 \% \pm$ $0.7 \%$, and subjects in the MDI group had a reduction of $-0.6 \% \pm 0.8 \%$. The baselineadjusted difference was $-0.1 \%$ ( $95 \% \mathrm{CI}-0.5$ to 0.3 ).

In a randomized, cross-over trial Bruttomesso et al [20] compared CSII and MDI with insulin glargine in type 1 diabetic patients who were well controlled using CSII for a minimum of six months. Patients were randomized to either stay on CSII or switch to 
MDI therapy for the first four months of the trail. After four months, subjects switched groups and started the opposite therapy for an additional four months. Data was collected from thirty-nine patients. Total daily insulin dose was lower for patients receiving CSII therapy as compared to MDI therapy at the end of the trial. Patients on CSII had a mean insulin dose of 0.54 units $/ \mathrm{kg}$ of body weight \pm 0.13 as compared to 0.63 units $/ \mathrm{kg}$ of body weight \pm 0.15 for patients on MDI therapy. At the end of the trial, it was determined that there was no significant difference between the two groups in relation to decrease in $\mathrm{HbA}_{1 \mathrm{c}}$ levels. Over all subjects, $\mathrm{HbA}_{1 \mathrm{c}}$ decreased over the study from baseline; $7.6 \% \pm$ 0.8 to $7.4 \% \pm 0.7 \%$. However, $\mathrm{HbA}_{1 \mathrm{c}}$ remained stable during both treatments.

\section{Conclusion}

Both MDI and CSII therapy help diabetic patients achieve as near-normal blood glucose values as possible. However, after numerous clinical trials, it remains unclear which treatment option is best in reducing $\mathrm{HbA}_{1 \mathrm{c}}$ levels and what factors may indicate one therapy over the other. While it remains unclear which treatment option is best at improving glycemic control, CSII has consistently been shown to decrease total daily insulin dose when compared to MDI, which is favorable. However, due to the myriad of advantages and disadvantages of both MDI and CSII and the inconsistencies in terms of glycemic control, more research is warranted to determine when the use of each therapy is indicated. 


\section{CHAPTER 3}

\section{METHODS}

\section{Background}

The early implementation of intensive diabetes management has become prevalent among type 1 diabetic patients since the Diabetes Control and Complications Trial was released in 1993. Multiple daily injections (MDI) and continuous subcutaneous insulin infusion (CSII), or insulin pump therapy, are the two intensive diabetes management therapies that are utilized when managing type 1 diabetes. With the importance of intensive diabetes managementx, and the availability of two different therapy options, it has become imperative that further research is conducted to determine for which patients each therapy is indicated. By understanding characteristics of patients that will make them more or less successful on CSII and MDI therapy, physicians and other health care providers will be able to make a more educated treatment decision, and they can help their patients better manage diabetes. This study sought to answer the following questions:

1. Are patients on multiple daily injections more or less successful after switching to continuous subcutaneous insulin infusion as measured by hemoglobin $\mathrm{A}_{1 \mathrm{c}}$, insulin dose change, and weight change? 
2. Can it be predicted, based on patient characteristics, which patients will be most successful on an insulin pump?

\section{Subjects}

The sample population for this study included patients at The Ohio State University Medical Center Division of Endocrinology, Diabetes \& Metabolism Insulin Pump Clinic who completed the switch from MDI therapy to CSII therapy under the guidance of the clinic staff between May 2005 and August 2009. We worked closely with the clinical program manager at the clinic, who assisted with gaining access to pertinent patient information for the study. The subjects were selected based on their acceptance into the insulin pump clinic, and both men and women over the age of eighteen with type 1 diabetes were included in the study. Additionally, to be included in the study, subjects' post-pump HbA1c assessment had to occur between 90 and 180 days following pump initiation. Patients with type 2 diabetes, those under the age of 18 , and patients whose post-pump $\mathrm{HbA}_{1 \mathrm{c}}$ value was collected less than 90 days or greater than 180 days following pump initiation were excluded from analysis. This study was approved by the Institutional Review Board (IRB) at The Ohio State University with expedited status (Appendix A) .

\section{The Ohio State University Division of Endocrinology, Diabetes \& Metabolism Insulin Pump Clinic Program}

The Ohio State University insulin pump clinic operates based on physician and nurse practitioner referrals, both from physicians associated with The Ohio State University Medical Center Division of Endocrinology, Diabetes \& Metabolism and 
physicians outside of Ohio State. When patients are referred to the clinic, they remain under the care of the clinic staff throughout their entire transition from MDI to CSII therapy, as well as through post-education classes.

Prior to transitioning to CSII therapy, patients must complete pre-pump requirements at the clinic. Before 2008, patients were required to attend an appointment at the clinic and meet with a nurse and dietitian. At this visit, patient information was collected including medical history, current insulin regimen, diet history, and a twenty four hour recall. Beginning in 2008, the pre-pump requirements changed. From January of 2008 onward, patients were required to attend two separate group classes two weeks apart which covered diabetes self-management topics, including insulin regimens, carbohydrate counting, blood glucose monitoring, exercise, and short and long term glycemia issues regarding prevention and treatment. After the pre-pump education, both sets of patients, those who attended a one-on-one counseling session prior to January of 2008 and those who attended two group classes after January of 2008, proceeded through the program identically.

After completing the pre-pump requirements, patients could begin insulin pump therapy. Patients, through the guidance of clinic staff, chose the appropriate insulin pump for their personal needs. After a patient had his or her insulin pump, a training and salinestart session was scheduled. During this session, the patient was trained on the use of the pump by a certified trainer from the pump company, and the patient was then given the opportunity to start using the pump with a saline solution. This allowed patients to 
familiarize themselves with the pump without the fear of misdosing insulin. During this time, usually three to seven days, the patient continued to administer injections but, at the same time, dose the saline from the pump.

After three to seven days using saline in the pump, the patient returned to the clinic to meet with a clinic staff member who worked with the patient to begin the true insulin pump start. At this visit, the clinician reviewed the pump with the patient, assisted the patient in changing his or her insertion site, and set the insulin pump with the correct insulin regimen as determined by the clinician.

Following pump initiation, patients were required to complete a one-week followup session with the clinician as well as three group education classes. These classes were aimed at helping the patient better utilize his or her pump and covered the following topics: mechanics and advanced nutrition, infusion sets and pattern management, and advanced carbohydrate counting. During this time, patients had weekly contact with a clinical staff member, either through phone or e-mail contact, to make adjustments to their insulin regimen based on food and blood glucose logs that the patient provided to the clinician. When the patient completed all post-pump education classes, a completion letter was composed by a clinical staff member detailing the patient's transition from MDI to CSII therapy. This letter was provided to the referring physician. If all posteducation classes were not completed, the clinical staff member still composed a completion letter and provided this to the referring physician. In the letter, the uncompleted requirements were noted. 


\section{Data Collection}

The data was collected on study specific case report forms (Appendix B). The data used for this study was collected during patient visits to the insulin pump clinic at The Ohio State University Medical Center. $\mathrm{HbA}_{1 \mathrm{c}}$ values were obtained every three months for each patient during the duration of their involvement with the clinic, starting as close to the insulin pump start date as possible. Blood was drawn at the insulin pump clinic and was sent to a central lab for analysis. The initial $\mathrm{HbA}_{1 \mathrm{c}}$ value was obtained prior to insulin pump start and the final $\mathrm{HbA}_{1 \mathrm{c}}$ level was obtained after pump initiation, varying between three and six months after the insulin pump start date. A weight was obtained for patients at each visit to the insulin pump clinic. The initial weight used was obtained at the first clinic visit, and the final weight used was the weight obtained at the patient's final visit to the insulin pump clinic. Each patient's insulin regimen was discussed and recorded at his or her initial visit to the insulin pump clinic. The final regimen was documented by the insulin pump clinician in the completion letter written for the patient's physician. Other data, including age, duration of diabetes, age at diagnosis, and complications were obtained by clinicians from the patient's medical record and through questionnaires filled out by the patient at his or her initial clinic visit.

\section{Statistical Analysis}

The primary outcome assessed in this study was the $\mathrm{HbA}_{1 \mathrm{c}}$ level before and after the switch to CSII. The baseline measure was obtained prior to initiation of CSII and the follow-up was three to six months after initiation. As $\mathrm{HbA}_{1 \mathrm{c}}$ values change slowly over time (up to a three month lag), patients assessed soon after pump initiation may not have experienced measurable improvement. Patients were included in the analysis if their post- 
pump $\mathrm{HbA}_{1 \mathrm{c}}$ assessment was between 90 and 180 days following pump initiation. If the post-pump $\mathrm{HbA}_{1 \mathrm{c}}$ assessment was less than 90 days or greater than 180 days following pump initiation, subjects were excluded from analysis. For subjects included in the study, a paired t-test was used to evaluate the primary hypothesis. If a conservative estimate of the standard deviation of the differences is assumed to be $1.5 \%$, a sample of 73 patients would provide $80 \%$ power to detect a clinically meaningful difference of $0.5 \%(\alpha=$ $0.05)$.

To determine whether external factors were related to a successful reduction in $\mathrm{HbA}_{1 \mathrm{c}}$ after pump initiation, the $\mathrm{HbA}_{1 \mathrm{c}}$ difference pre to post was used as the outcome in a linear regression model, and potential covariates were evaluated univariately for their predictive ability. The following covariates were explored in the model: age, gender, duration of diabetes, age at diagnosis, average insulin pre-pump (raw units and per $\mathrm{kg}$ of body weight), weight, type of insulin used, pump type, and the presence of various complications. As mentioned, in 2008 the educational component in the program was altered, thus, an indicator variable (before or after educational change) was included. 


\title{
CHAPTER 4
}

\section{PREDICTORS OF SUCCESS FOR ADULTS WITH TYPE 1 DIABETES ON CONTINUOUS SUBCUTANEOUS INSULIN INFUSION THERAPY: A RETROSPECTIVE REVIEW}

\begin{abstract}
Background/ Objective: Complications can ensue from uncontrolled type 1 diabetes, resulting in compromised quality and duration of life, and increased health care costs. The provision of insulin is achieved by multiple daily injections (MDI) or by insulin pump through continuous subcutaneous insulin infusion (CSII). The primary objective was to determine the difference between hemoglobin $\mathrm{A}_{1 \mathrm{c}}\left(\mathrm{HbA}_{1 \mathrm{c}}\right)$ before and after the switch from MDI to CSII therapy. Methods: In this retrospective medical record review, paired t-tests were used for all of the pre-post comparisons. To determine whether external factors were related to a successful reduction in $\mathrm{HbA}_{1 \mathrm{c}}$ after pump initiation, the pre-post $\mathrm{HbA}_{1 \mathrm{c}}$ difference was used as the outcome in a linear regression model, and potential patient characteristic covariates were evaluated univariately for their predictive ability: age, gender, duration of diabetes, age at diagnosis, average insulin pre-pump units (absolute and per kg body weight), weight, insulin and pump types, and the presence of various complications. Of the 107 subjects initially identified, 42 subjects met inclusion
\end{abstract}


criteria. Results: The average $\mathrm{HbA}_{1 \mathrm{c}}$ of participants decreased by $0.55 \%$ from pre-pump values $(\mathrm{P}=0.0001)$, the average daily insulin dose per kilogram of body weight decreased by $0.061 \mathrm{U} / \mathrm{kg},(\mathrm{P}=0.0029)$, and weight decreased by $0.07 \mathrm{~kg}$. ( $\mathrm{P}=0.86)$. None of the continuous or categorical variables were found to be statistically significant at predicting a pre- to post-reduction in $\mathrm{HbA}_{1 \mathrm{c}}$ levels. Conclusions: This study suggests that all study participants, regardless of patient characteristics, benefited from the transition from MDI to CSII therapy.

\section{Introduction and Statement of Purpose}

Diabetes has become a serious health problem in the United States over the last several decades, and the number of Americans inflicted with diabetes is continually rising. It is estimated that eight percent of the population, or about 23.6 million adults and children in the United States, have some form of diabetes [1]. Because the incidence rate of diabetes is increasing, diabetic complications are also on the rise. Several serious diabetic complications can arise from long-standing diabetes, especially when those with diabetes exhibit poor glycemic control. These complications include cardiovascular disease, hypertension, dyslipidemia, neuropathy, nephropathy, and retinopathy. Diabetic complications can decrease quality of life, increase health care costs, and result in a shortened life for an individual with diabetes. However, in the Diabetes Control and Complications Trial [2], good glycemic control, achieved through intensive diabetes management, resulted in a lowered incidence of diabetic complications. After the results 
of this landmark study were released, it has become even more crucial to determine which methods of diabetic management result in the most success for optimal glycemic control.

Two intensive diabetes management therapies are available, multiple daily injections (MDI) and continuous subcutaneous insulin infusion (CSII), also known as insulin pump therapy. Although both methods are widely used, it is unclear which treatment option is superior in terms of achieving optimal glycemic control. Because both treatment options have distinct advantages and disadvantages, working with patients individually and determining the best treatment option may be most effective when considered on a case by case basis. The development of criteria as to when each treatment option is indicated may help assist health care providers when determining a treatment option. Because diabetes has become such a prevalent disease in our country, it is imperative that the best treatment options are employed to help control the long-term effects of diabetes, optimize glycemic control, and improve the overall quality of life for diabetics.

The purpose of this study was to evaluate whether individuals with type 1 diabetes on MDI were more or less successful after switching to insulin pump therapy as measured by hemoglobin $\mathrm{A}_{1 \mathrm{c}}\left(\mathrm{HbA}_{1 \mathrm{c}}\right)$, insulin dose change, and weight change. Additionally, we sought to determine if it can be predicted, based on patient characteristics, which patients will be most successful on an insulin pump. Patient characteristics evaluated included age, gender, duration of diabetes, age at diagnosis, average insulin dose prior to pump therapy, average insulin dose per kilogram of body 
weight prior to pump therapy, weight, type of insulin administered in the insulin pump, type of insulin pump, and the presence of diabetic complications or concomitant conditions.

\section{Subjects and Methods}

\section{Participants and sample size}

This study was a retrospective medical record review that included patients from The Ohio State University Medical Center Division of Endocrinology, Diabetes \& Metabolism Insulin Pump Clinic who completed the switch from MDI therapy to CSII therapy under the guidance of the clinic staff between May 2005 and August 2009. The subjects were selected based on their acceptance into the insulin pump clinic, and both men and women over the age of eighteen with type 1 diabetes were included in the study. Additionally, to be included in the study, subjects' post-pump $\mathrm{HbA}_{1 \mathrm{c}}$ assessment had to occur between 90 and 180 days following pump initiation. Patients with type 2 diabetes, those under the age of eighteen, and patients whose post-pump $\mathrm{HbA}_{1 \mathrm{c}}$ value was collected less than 90 days or greater than 180 days following pump initiation were excluded from analysis. After evaluation of available medical records, it was determined that forty-two patients satisfied all inclusion criteria and were included in the final analysis (Figure 4.1).

This study was approved by the Institutional Review Board (IRB) at The Ohio State University with expedited status (Appendix A).

\section{Insulin pump clinic program}

Patients switching from MDI to CSII therapy at the clinic receive extensive education, both prior to and following the transition to insulin pump therapy. Before 
transitioning to CSII therapy, patients must complete pre-pump requirements at the clinic. Prior to 2008, patients were required to attend an appointment at the clinic and meet with a nurse and dietitian. At this visit, patient information was collected including medical history, current insulin regimen, diet history, and a twenty-four hour recall. Beginning in 2008, the pre-pump requirements changed. From January 2008 onward, patients were required to attend two separate group classes two weeks apart which covered diabetes self-management topics, including insulin regimens, carbohydrate counting, blood glucose monitoring, exercise, and short- and long-term glycemia issues regarding prevention and treatment. After pre-pump education, both sets of patients, those who attended a one-on-one counseling session prior to January of 2008 and those who attended two group classes after January of 2008, proceeded through the program identically.

After completing the pre-pump requirements, patients could begin insulin pump therapy. Patients, through the guidance of clinic staff, chose the appropriate insulin pump for their personal needs. Following pump initiation, patients were required to attend a one-week follow-up session at the clinic as well as three group education classes, which were aimed at helping the patient better utilize his or her pump. The following topics were covered: mechanics and advanced nutrition, infusion sets and pattern management, and advanced carbohydrate counting. During this time, patients had weekly contact with a clinic staff member to make adjustments to their insulin regimen based on food and blood glucose logs. When the patient completed all post-pump education classes, a 


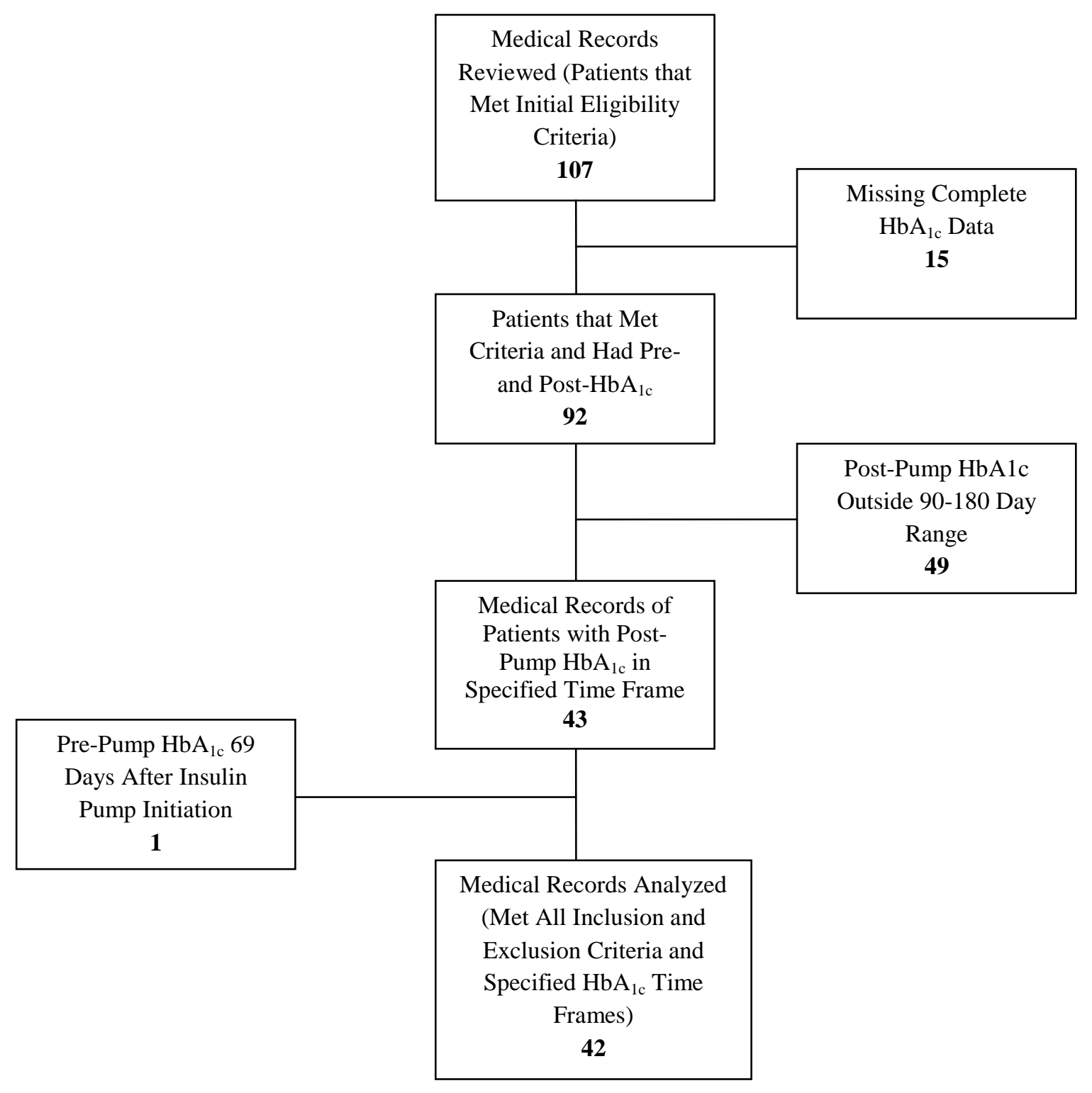

Figure 4.1: Patient Flow Chart 
completion letter was composed detailing the patient's transition from MDI to CSII therapy. If the patient failed to meet all program requirements, it was documented in the letter.

\section{Data collection at the insulin pump clinic}

The data used for this study was collected during patient visits to the insulin pump clinic at The Ohio State University Medical Center. $\mathrm{HbA}_{1 \mathrm{c}}$ values were obtained every three months for each patient during the duration of his or her involvement with the clinic, starting as close to the insulin pump start date as possible. Blood was drawn at the insulin pump clinic and was sent to a central lab for analysis. The initial $\mathrm{HbA}_{1 \mathrm{c}}$ value was obtained prior to insulin pump start and the final $\mathrm{HbA}_{1 \mathrm{c}}$ level was obtained after pump initiation, varying between three and six months after the insulin pump start date. A weight was obtained for patients at each visit to the insulin pump clinic. The initial weight used was obtained at the first clinic visit, and the final weight used was the weight obtained at the patient's final visit to the insulin pump clinic. Each patient's insulin regimen was discussed and recorded at his or her initial visit to the clinic. The final regimen was documented by the insulin pump clinician in the completion letter written for the patient's physician. Other data, including age, duration of diabetes, age at diagnosis, and complications were obtained by clinicians from the patient's medical record and through questionnaires filled out by the patient at his or her initial clinic visit.

\section{Statistical Analysis}

The primary outcome assessed in this study was the $\mathrm{HbA}_{1 \mathrm{c}}$ level before and after the switch to CSII. The baseline measure was obtained prior to initiation of CSII and the follow-up was three to six months after initiation. As $\mathrm{HbA}_{1 \mathrm{c}}$ values change slowly over 
time (up to a three month lag), patients assessed soon after pump initiation may not have experienced measurable improvement. Patients were included in the analysis if their post-pump $\mathrm{HbA}_{1 \mathrm{c}}$ assessment was between 90 and 180 days following pump initiation. If the post-pump $\mathrm{HbA}_{1 \mathrm{c}}$ assessment was less than 90 days or greater than 180 days following pump initiation, subjects were excluded from analysis. For subjects included in the study, a paired t-test was used to evaluate the primary hypothesis.

To determine whether external factors were related to a successful reduction in $\mathrm{HbA}_{1 \mathrm{c}}$ after pump initiation, the $\mathrm{HbA}_{1 \mathrm{c}}$ difference pre to post was used as the outcome in a linear regression model, and potential covariates were evaluated univariately for their predictive ability. The following covariates were explored in the model: age, gender, duration of diabetes, age at diagnosis, average insulin pre-pump (raw units and per $\mathrm{kg}$ of body weight), weight, type of insulin used, insulin pump type, and the presence of various complications. As mentioned, in 2008 the educational component in the program was altered, thus, an indicator variable (before or after educational change) was included.

\section{Results}

\section{Patient flow and baseline characteristics}

Patient flow is described in Figure 1. Of the 107 subjects initially measured, sixtyfour did not meet inclusion criteria and were eliminated from the analysis. Additionally, one subject was eliminated due to an anomaly in the timing of the subject's pre-insulin pump $\mathrm{HbA}_{1 \mathrm{c}}$ measure, which occurred sixty-nine days after CSII initiation. This resulted in a total study sample size of forty-two subjects. Baseline characteristics are described in Table 4.1. 


\begin{tabular}{lcc}
\hline Characteristic & n & Value* \\
\hline Sex (Males/Females) & 42 & $18 / 24$ \\
\hline Age (years) & 42 & $40.4 \pm 13$ \\
\hline Age at diagnosis (years) & $41 * *$ & $17.3 \pm 12.1$ \\
\hline Duration of diabetes (years) & $41 * *$ & $22.7 \pm 13$ \\
\hline Daily insulin dose (U/day) & 42 & $45.9 \pm 17$ \\
\hline Daily insulin per kg (U/kg) & 42 & $0.6 \pm 0.2$ \\
\hline Weight (kg) & 42 & $76.5 \pm 14.9$ \\
\hline HbA ${ }_{1 \mathrm{c}}(\%)$ & 42 \\
\hline Data are presented as means \pm SD \\
* One patient was missing data and not included in the analysis
\end{tabular}

\section{Table 4.1: Baseline Characteristics}

There was a higher percentage of female subjects (57\%) than male subjects (43\%) in the sample, and the mean age of participants was approximately forty years. Additionally, the mean duration of diabetes was approximately twenty-three years, and the mean age at diabetes diagnosis was approximately seventeen years. The average daily insulin dose was 45.9 units, and the average daily insulin dose per kilogram of body weight was 0.6 $\mathrm{U} / \mathrm{kg}$. In addition, the mean weight of the subjects was $76.5 \mathrm{~kg}$, and the mean $\mathrm{HbA}_{1 \mathrm{c}}$ at baseline was $7.92 \%$.

\section{$\mathrm{HbA}_{1 c}$, insulin dose change, and weight change}

The average $\mathrm{HbA}_{1 \mathrm{c}}$ of participants decreased by $0.55 \%$ from $7.92 \pm 0.92 \%$ prior to the initiation of CSII to $7.37 \pm 1.16 \%$ post CSII initiation. This was a statistically 
significant reduction $(\mathrm{P}=0.0001)$ (Figure 4.2). Additionally, the average weight of subjects decreased from pre- to post-insulin pump initiation as did the average insulin dose per kilogram of body weight. The reduction in the insulin dose per kilogram of body weight from pre- to post-insulin pump initiation was 0.061 units $/ \mathrm{kg}(0.6 \pm 0.17 \mathrm{U} / \mathrm{kg}$ to $0.54 \pm 0.13 \mathrm{U} / \mathrm{kg})$, which was a statistically significant reduction $(\mathrm{P}=0.0029)$ (Figure 4.3). Conversely, the average post-insulin pump weight was $0.07 \mathrm{~kg}$ less than the preinsulin pump weight $(76.5 \pm 14.9 \mathrm{~kg}$ to $76.43 \pm 15.1 \mathrm{~kg})$, which did not reach statistical significance $(\mathrm{P}=0.86)$ (Figure 4.4); however, the standard deviation for this outcome variable was large (2.74).

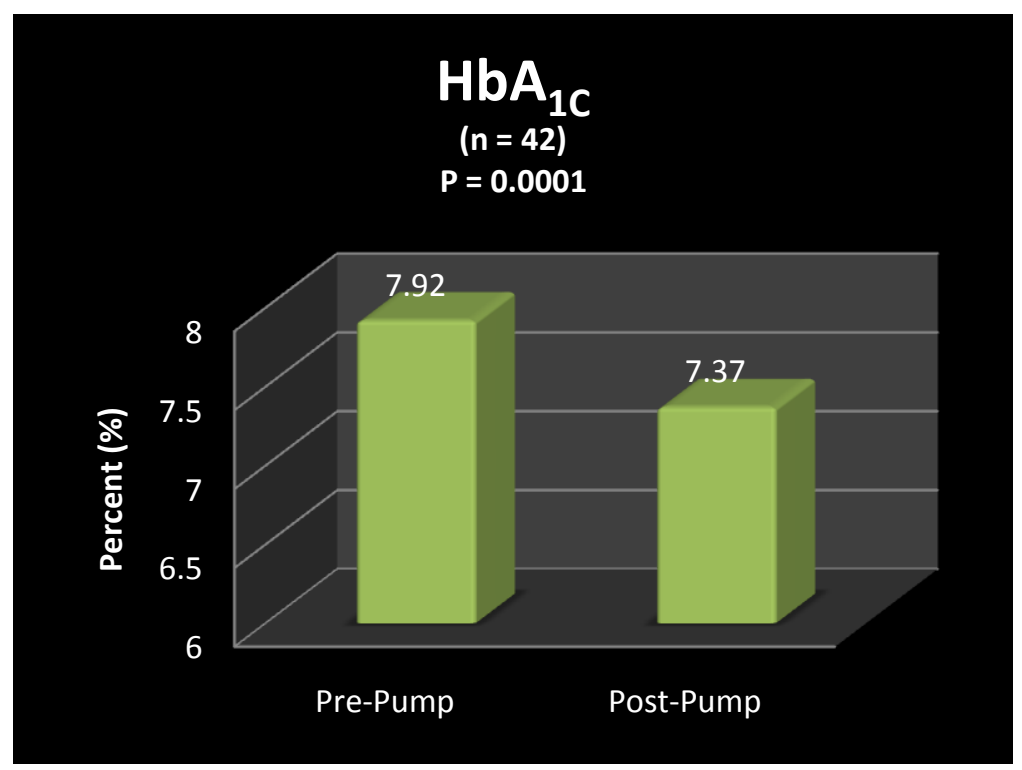

Figure 4.2: $\mathrm{HbA}_{1 \mathrm{c}}$ Pre- and Post-Pump Initiation 


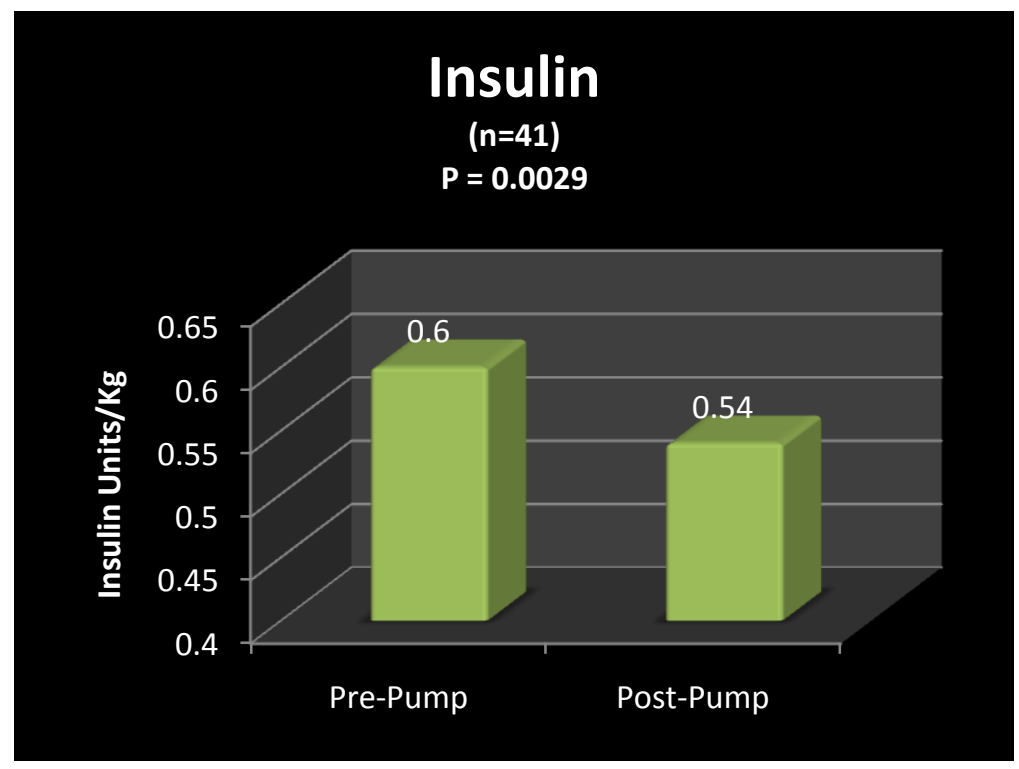

Figure 4.3: Insulin Units Pre- and Post-Pump Initiation

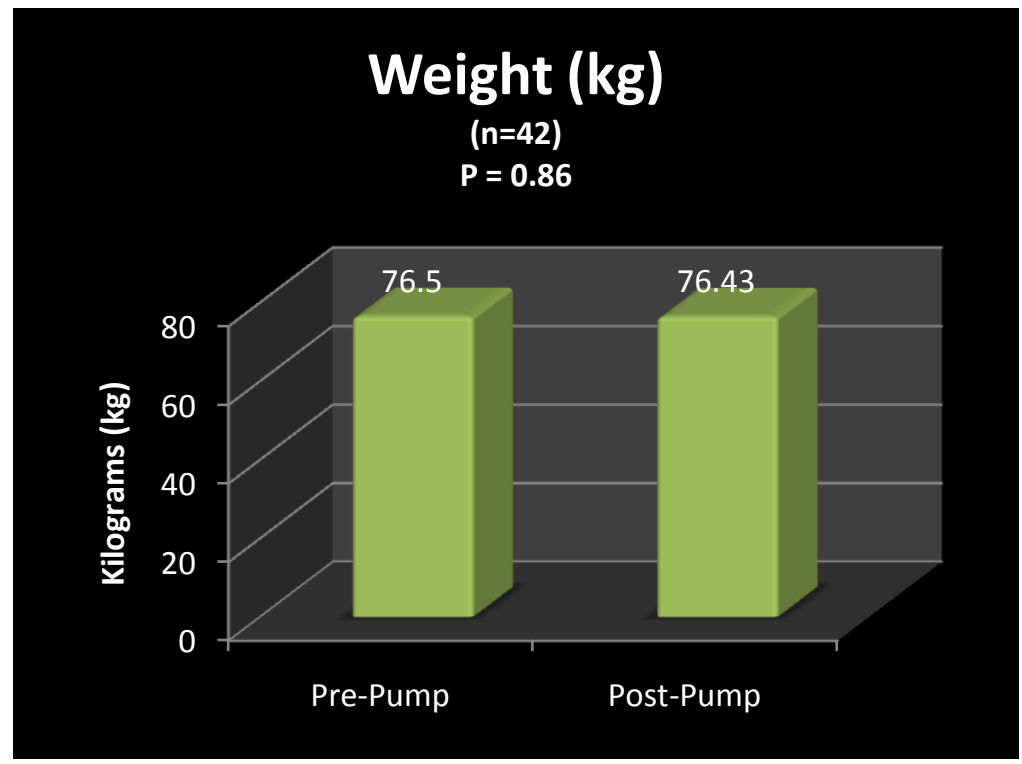

Figure 4.4: Weight Pre- and Post-Pump Initiation 


\section{Continuous and categorical predictors of success}

None of the continuous predictors, as previously described in Table 4.1, were found to be statistically significant in terms of predicting a pre- to post-reduction in $\mathrm{HbA}_{1 \mathrm{c}}$ values (Appendix C).

The categorical predicators evaluated included gender, type of insulin pump, type of insulin, diabetic complications, and year in which insulin pump education occurred. There were more female subjects (53\%) than male subjects (43\%). Thirty-four participants (81\%) were using Medtronic brand pumps, six (14\%) were using Deltec Cozmo, and two (5\%) were using an OmniPod pump. The majority of participants used Lispro insulin in their insulin pump (66.67\%) with fewer patients using either Aspart insulin $(28.57 \%)$ or Glulisine insulin (4.76\%). Of the forty-two study participants, 10 participants (24\%) had no known diabetic complications while 32 participants (76\%) had at least one documented diabetic complication with neuropathy (25\%), retinopathy (22.22\%), hyperlipidemia (22.22\%), and hypertension (9.72\%) being the four most prevalent diabetic complications in this study population. Additionally, thirty-two subjects (76\%) had pre-CSII education prior to 2008 while for ten subjects (24\%) prepump education occurred in 2008 or after, after the modification in education requirements.

None of the categorical variables (Appendix C) were found to be significant predictors when using $\mathrm{HbA}_{1 \mathrm{c}}$ difference (post minus pre) as the outcome.

\section{Discussion}

This study suggests that individuals who switch from MDI to CSII therapy will see a significant reduction in both $\mathrm{HbA}_{1 \mathrm{c}}$ levels and insulin units per kilogram of body 
weight. $\mathrm{HbA}_{1 \mathrm{c}}$ decreased in this study population by $0.55 \%$, and the reduction in units per kilogram of body weight was $0.061 \mathrm{U} / \mathrm{kg}$ after the initiation of CSII therapy.

Additionally, none of the categorical or continuous variables used to determine whether patient characteristics could predict success on the insulin pump in terms of $\mathrm{HbA}_{1 \mathrm{c}}$ reduction, were significant. This suggests that all subjects benefited from the transition to CSII therapy, not just a specific segment of the study sample.

Previous studies comparing CSII to MDI therapy have had varying results in terms of determining the superiority of the two intensive diabetes management therapies in reducing $\mathrm{HbA}_{1 \mathrm{c}}$ levels. Several recent studies have found that $\mathrm{HbA}_{1 \mathrm{c}}$ is reduced in patients on CSII as compared to MDI therapy [9, 13-16]. Additionally, a meta-analysis [21] was recently published which compared CSII to MDI with $\mathrm{HbA}_{1 \mathrm{c}}$ used as the primary outcome for assessing efficacy on glycemic control. This meta-analysis found that $\mathrm{HbA}_{1 \mathrm{c}}$ was lower with CSII therapy as compared to MDI therapy, with a $0.2 \%$ reduction in studies using insulin Lispro and a $0.6 \%$ reduction in studies using insulin Aspart . However, this analysis included studies with both pediatric and adult populations, while the current study only considered adult populations. On the contrary, multiple recent studies comparing CSII to MDI have found that there was no statistically significant difference in $\mathrm{HbA}_{1 \mathrm{c}}$ levels when comparing the two therapies $[11,17,19,20]$. Unlike this study, which examined patients with diverse characteristics due to its retrospective design, many studies previously comparing MDI and CSII have had populations with some degree of homogeny, including baseline $\mathrm{HbA}_{1 \mathrm{c}}$ level and type of insulin used in the insulin pump, which may have impacted the results. 
Two previous studies $[14,16]$ compared $\mathrm{HbA}_{1 \mathrm{c}}$ levels between MDI and CSII therapy in patients who were unable to maintain desirable $\mathrm{HbA}_{1 \mathrm{c}}$ levels while on MDI therapy. In both of these studies, subjects experienced significant improvements in $\mathrm{HbA}_{1 \mathrm{c}}$ levels after the switch to CSII therapy. This result would be expected because it has been shown that patients with higher baseline $\mathrm{HbA}_{1 \mathrm{c}}$ levels experience a greater benefit from switching to CSII therapy from MDI therapy than do patients with more optimal baseline $\mathrm{HbA}_{1 \mathrm{c}}$ values [18]. The current study, which did not specify baseline $\mathrm{HbA}_{1 \mathrm{c}}$ level as either an inclusion or exclusion criteria, may demonstrate that a larger patient population with more diverse baseline $\mathrm{HbA}_{1 \mathrm{c}}$ levels could benefit from CSII initiation.

Due to the retrospective nature of this study, the type of insulin utilized by patients in their insulin pump was not predetermined. This is contrary to several recent studies comparing MDI to CSII therapy that specified insulin Lispro for use by patients during the duration of the study $[13,17,19]$. The current study had multiple subjects using either Lispro or Aspart insulin in their pumps and two patients using Glulisine insulin. Despite the heterogeneous population for this variable, the study results still indicated that significantly superior glycemic control was achieved in this patient population when utilizing CSII therapy as compared to MDI therapy.

Although strict exclusion criteria were employed in the current study in regards to the timing of post-insulin pump $\mathrm{HbA}_{1 \mathrm{c}}$ date of measurement, inclusion or exclusion criteria related to patient readiness for the demands of CSII therapy or additional careful selection procedures for patients beginning CSII were not possible because patients were retrospectively considered for inclusion in the analysis. In a recent study conducted by Karagianni et al [9], the authors stated that the careful selection of patients for transition 
to CSII therapy from MDI therapy may have impacted the results of their study, influencing the improvement seen in $\mathrm{HbA}_{1 \mathrm{c}}$ values of patients on CSII therapy as compared to those on MDI therapy. Contrary to the Karagianni study, the outcome of the current study further demonstrates that CSII is beneficial in terms of achieving optimal glycemic control regardless of the ability to carefully monitor patient selection.

In the current study, none of the categorical or continuous predictors used to assess whether patient characteristics could predict success on CSII in terms of $\mathrm{HbA}_{1 \mathrm{c}}$ reduction were significant. This was the first study known to the authors that examined whether specific patient characteristics could determine success on an insulin pump. This is a significant result, because it is the first study to suggest that all patients, regardless of characteristics including gender, age, complications, type of insulin pump, duration of diabetes, and age at diagnosis, among others, see more benefit with CSII therapy than with MDI therapy in terms of glycemic control.

This study also examined insulin dose per kilogram. The results of this study confirmed the findings in previous studies that insulin dose per kilogram of body weight is decreased in patients on CSII as compared to MDI therapy $[16,17,20]$. This is likely true because it has been shown that absorption rate can vary by as much as $52 \%$ in longacting insulin, resulting in unexplained hypo- or hyperglycemic events [8]. On the other hand, the absorption rate of short-acting insulins is thought to vary by only $3 \%$ [8]. Insulin pumps use only short-acting insulin, while individuals on MDI must use both short- and long-acting insulins, causing more variable absorption, likely leading to a higher insulin requirement. In addition, the small, continual dosing of short-acting insulin 
utilized in insulin pumps more precisely mimics the insulin secretion of the pancreas, which may also contribute to the lower insulin requirements often observed in CSII therapy.

There were several limitations to the current study. First, the retrospective design made it difficult to control patient variables. For instance, subjects were utilizing various pumps based on personal preference as selected at the time of CSII initiation.

Additionally, a large number of subjects were excluded because a realistic time frame for post-insulin pump $\mathrm{HbA}_{1 \mathrm{c}}$ measurements had to be established to ensure a uniform measurement for the primary outcome variable. However, despite the large number of excluded subjects, the study still yielded a statistically significant reduction in $\mathrm{HbA}_{1 \mathrm{c}}$ levels for patients after they had switched to CSII therapy. Another limitation was the inability to follow up on missing data because the retrospective design made it difficult to track patient information that was no longer accessible. For instance, some patients had left the practice or the physician had moved locations, making any missing data inaccessible.

\section{Conclusion}

The results of this study suggest that all patients in this population, regardless of their baseline characteristics, including age, gender, duration of diabetes, age at diagnosis, pre-insulin pump insulin dose, weight, type of insulin used, type of insulin pump, and the presence of diabetic complications, benefited from the switch to CSII therapy from MDI therapy in terms of improved glycemic control as measured by $\mathrm{HbA}_{1 \mathrm{c}}$. Additionally, CSII therapy resulted in a reduction in insulin dose per kilogram of body 
weight when compared with MDI. These results are encouraging and indicate the need for future research to further elucidate the relationship between baseline characteristics and success on an insulin pump. 


\section{CHAPTER 5}

\section{SUMMARY AND CONCLUSIONS}

\section{Results Summary}

The results of this study suggest that both $\mathrm{HbA}_{1 \mathrm{c}}$ and insulin units per kilogram of body weight are statistically significantly reduced in patients with type 1 diabetes who switch from CSII to MDI therapy. $\mathrm{HbA}_{1 \mathrm{c}}$ was reduced by $0.55 \%$ and insulin units per kilogram of body weight were reduced by $0.061 \mathrm{U} / \mathrm{kg}$ in this study population, both of which have clinical significance. However, the weight of the subjects, which was reduced by $0.07 \mathrm{~kg}$ after the transition to CSII therapy, was not a statistically significant reduction. Additionally, none of the continuous or categorical variables were significant when used to determine whether success on an insulin pump, as measured by the reduction in $\mathrm{HbA}_{1 \mathrm{c}}$ levels, could be predicated based on patient characteristics. As stated previously, the results of this study are significant because they suggest that all patients, regardless of baseline characteristics, benefit from the transition to CSII therapy.

\section{Discussion}

As previously discussed, many prior studies have been conducted that compare the efficacy of CSII and MDI. A number of these studies suggest that CSII is superior to MDI in terms of achieving more optimal glycemic control as measured by $\operatorname{HbA}_{1 c}[9,13-$ 
16]. On the contrary, several other recent studies suggest that there is not a statistically significant difference between the two intensive diabetes management therapies at reducing $\mathrm{HbA}_{1 \mathrm{c}}$ levels $[11,17,19,20]$. Many of the above studies considered patients with some degree of homogeny, such as including only patients with elevated baseline $\mathrm{HbA}_{1 \mathrm{c}}$ levels, carefully hand selecting patients to transition to CSII who demonstrated a high degree of readiness for insulin pump transition, or utilizing only one type of insulin throughout the duration of the study. Although these study designs allow for researcher control, the inability to determine whether diverse populations of individuals with type 1 diabetes benefit from the transition to CSII therapy, as well as the lack of consensus as to whether CSII is more effective than MDI at reducing HbA1c levels, has left room for controversy surrounding which therapy is indicated for which patients. The current study had a sample with diverse baseline characteristics due to its retrospective design, yet still showed a statistically significant reduction in $\mathrm{HbA}_{1 \mathrm{c}}$ levels and insulin units per kilogram of body weight after the switch to CSII therapy. These results are encouraging and indicate a need for future research to gain a more concrete understanding of the relationship between baseline characteristics and success on an insulin pump.

Two studies, a meta-analysis and a systematic review, were recently conducted that evaluated the efficacy of MDI and CSII in terms of glycemic control. The metaanalysis conducted by Monami et al [21] included randomized controlled trials conducted for a minimum of twelve weeks that compared MDI to CSII therapy in individuals with type 1 diabetes. Eleven studies met all inclusion criteria and were included in the metaanalysis, which found that $\mathrm{HbA}_{1 \mathrm{c}}$ was significantly reduced in patients on CSII as compared to MDI. Specifically, the meta-analysis found that $\mathrm{HbA}_{1 \mathrm{c}}$ was reduced by $0.2 \%$ 
with insulin Lispro $(\mathrm{P}=0.001)$ and $0.6 \%(\mathrm{P}=0.002)$ with insulin Aspart. Although this meta-analysis included studies with both pediatric and adult populations, and the current study evaluated only adults, the results are still significant. The results indicate not only that CSII is superior to MDI in terms of achieving more optimal glycemic control but also that insulin Lispro and insulin Aspart result in varying $\mathrm{HbA}_{1 \mathrm{c}}$ reductions in patients on CSII therapy. These results further indicate a need for additional research to evaluate the relationship between patient characteristics and success on an insulin pump.

A recently conducted systematic review by Misso et al [22] further confirms that CSII is superior to MDI therapy in terms of reducing $\mathrm{HbA}_{1 \mathrm{c}}$ levels. In the review, twentythree studies comparing MDI therapy to CSII therapy in patients with type 1 diabetes were evaluated to determine the efficacy of each diabetes management therapy. For inclusion in the review, the randomized trial had to compare MDI therapy with three or more daily injections to CSII therapy. After analyzing the twenty-three studies, it was concluded that CSII reduced $\mathrm{HbA}_{1 \mathrm{c}}$ by an additional $0.3 \%$ as compared to MDI. The authors of the review state that their findings provide some evidence that CSII is more effective than MDI at reducing $\mathrm{HbA}_{1 \mathrm{c}}$; however, they discuss a need for future research surrounding adverse events, morbidity, mortality, and the cost of each type of intervention.

\section{Limitations and Implications for Further Research}

As stated previously, the current study had several limitations, including the retrospective design that made it challenging to control patient variables, a large number of excluded subjects, and the inability to follow up on missing patient data. Despite the study limitations, the results of this study clearly indicate a need for future research to 
further elucidate the relationship between patient characteristics and success on an insulin pump. As health insurance costs continue to rise in our country, insurers are seeking areas where insurance coverage can be reduced. With the results of this study indicating that all patients benefit from CSII, future studies that investigate CSII therapy in patients with various characteristics may help to solidify the effectiveness of pump therapy, thereby ensuring future insurance coverage for patients with type 1 diabetes. Future research should include randomized controlled trials of longer duration with larger sample size. This will allow the researchers to more precisely control patient variables and, due to the design, will allow for easier access to all pertinent data from study participants. 


\section{REFERENCES}

1. American Diabetes Association Web site. http://www.diabetes.org/. Accessed July14, 2009.

2. The Diabetes Control and Complications Trial Research Group: The effect of intensive treatment of diabetes on the development and progression of long-term complications in insulin-dependent diabetes mellitus. N Engl J Med. 1993; 329: 977-986.

3. Mahan LK, Escott-Stump S. Krause's Food \& Nutrition Therapy, $12^{\text {th }}$ ed. St. Louis, MO: Saunders Elsevier, 2008.

4. Teuscher A. Insulin A Voice for Choice. Basel, Switzerland: Kargen, 2007.

5. Owens DR, MD. Human Insulin Clinical Pharmacological Studies in Normal Man. London: MTP Press Limited, 1986.

6. Allan FN. Diabetes Before and After Insulin. Medical History. 1972; 16: 266273.

7. Fauci AS, Braunwald E, Kasper DL, Hauser SL, Longo DL, Jameson JL, Loscalzo J. Harrison's Principles of Internal Medicine, $17^{\text {th }}$ ed.. New York: The McGraw-Hill Companies, Inc., 2008.

8. Bode BW, Sabbah HT, Gross TM, Fredrickson LP, Davidson PC. Diabetes Management in the New Millennium Using Insulin Pump Therapy. Diabetes Metab Res Rev. 2002; 18 (Suppl 1): S14-S20.

9. Karagianni P, Sampanis Ch, Katsoulis C, Miserlis Gr, Polyzos S, Zografou I, Stergiopoulos S, Douloumbakas I, Zamboulis Ch. Continuous Subcutaneous Insulin Infusion versus Multiple Daily Injections. Hippokratia. 2009; 13, 2: 9396.

10. Jeitler K, Horvath K, Berghold A, Gratzer TW, Neeser K, Pieber TR, Siebenhofer A. Continuous Subcutaneous Insulin Infusion versus Multiple Daily Insulin Injections in Patients with Diabetes Mellitus: Systematic Review and MetaAnalysis. Diabetologia. 2008; 51: 941-951. 
11. Hoogma RPLM, Spijker AJM, van Doorn-Scheele M, van Doorn TT, Michels RPJ, van Doorn RG, Levi M, Hoekstra JBL. Quality of Life and Metabolic Control in Patients with Diabetes Mellitus Type 1 Treated by Continuous Subcutaneous Insulin Infusion or Multiple Daily Insulin Injections. The Netherlands Journal of Medicine. 2004; 62, 10: 383-387.

12. Hunger-Dathe W, Braun A, Müller UA, Schiel R, Femerling M, Risse A. Insulin Pump Therapy in Patients with Type 1 Diabetes Mellitus: Results of the Nationwide Quality Circle in Germany (ASD) 1999-2000. Exp Clin Endocrinol Diabetes. 2003; 111: 428-434.

13. Hanaire-Broutin H, Melki V, Bessières-Lacombe S, Tauber JP. Comparison of Continuous Subcutaneous Insulin Infusion and Multiple Daily Injection Regimens Using Insulin Lispro in Type 1 Diabetic Patients on Intensified Treatment A Randomized Study. Diabetes Care. 2000; 23, 9: 1232-1235.

14. DeVries JH, Snoek FJ, Kostense PJ, Masurel N, Heine RJ. A Randomized Trial of Continuous Subcutaneous Insulin Infusion and Intensive Injection Therapy in Type 1 Diabetes for Patients with Long-Standing Poor Glycemic Control. Diabetes Care. 2002; 25, 11: 2074-2080.

15. Linkeschova R, Raoul M, Bott U, Berger M, Spraul M. Less Severe Hypoglycaemia, Better Metabolic Control, and Improved Quality of Life in Type 1 Diabetes Mellitus with Continuous Subcutaneous Insulin Infusion (CSII) Therapy; An Observational Study of 100 Consecutive Patients Followed for a Mean of 2 Years. Diabetic Medicine. 2002; 19: 746-751.

16. Giménez M, Conget I, Jansà M, Vidal M, Chiganer G, Levy I. Efficacy of Continuous Subcutaneous Insulin Infusion in Type 1 Diabetes: A 2-Year Perspective Using the Established Criteria for Funding From a National Health Service. Diabetic Medicine. 2007; 24: 1419-1423.

17. Tsui E, Barnie A, Ross S, Parkes R, Zinman B. Intensive Insulin Therapy with Insulin Lispro A Randomized Trial of Continuous Subcutaneous Insulin Infusion versus Multiple Daily Insulin Injection. Diabetes Care. 2001; 24, 10: 1722-1727.

18. Retnakaran R, Hochman J, DeVries JH, Hanaire-Broutin H, Heine RJ, Melki V, Zinman B. Continuous Subcutaneous Insulin Infusion versus Multiple Daily Injections The Impact of Baseline A1c. Diabetes Care. 2004; 27, 11: 2590-2596.

19. Bolli GB, Kerr D, Thomas R, Torlone E, Sola-Gazagnes A, Vitacolonna E, Selam JL, Home PD. Comparison of a Multiple Daily Insulin Injection Regimen (Basal Once-Daily Glargine Plus Mealtime Lispro) and Continuous Subcutaneous Insulin Infusion (Lispro) in Type 1 Diabetes. Diabetes Care. 2009; 32, 7: 11701176. 
20. Bruttomesso D, Crazzolara A, Maran A, Costa S, Dal Pos M, Girelli A, Lepore G, Aragona M, Iori E, Valentini U, Del Prato S, Tiengo A, Buhr A, Trevisan R, Baritussio A. In Type 1 Diabetic Patients with Good Glycaemic Control, Blood Glucose Variability is Lower during Continuous Subcutaneous Insulin Infusion than during Multiple Daily Injections with Insulin Glargine. Diabetic Medicine. 2008; 25: 326-332.

21. Monami M, Lamanna C, Marchionnoi N, Mannucci E. Continuous Subcutaneous Insulin Infusion Versus Multiple Daily Insulin Injections in Type 1 Diabetes: A Meta-Analysis. Acta Diabetol. Jun 62009 [Epub ahead of print].

22. Misso ML, Egberts KJ, Page M, O'Connor D, Shaw J. Continuous Subcutaneous Insulin Infusion (CSII) Versus Multiple Daily Injections for Type 1 Diabetes Mellitus. Cochrane Database Syst Rev. 2010 Jan 20; (1):CD005103. [Abstract] 


\section{APPENDIX A}

Institutional Review Board Approval Letter 
Protocol Number: Protocol Title:

$\begin{array}{ll}\text { Type of Review: } & \text { Initial Review - expedited } \\ \text { IRB Staff Contact: } & \text { Jennifer Spohn } \\ & 247-1562 \\ & \text { spohn.31@osu.edu }\end{array}$

$2009 \mathrm{H} 0258$

spohn.31@osu.edu
PREDICTORS OF SUCCESS FOR ADULTS WITH TYPE 1 DIABETES ON

CONTINUOUS SUBCUTANEOUS INSULIN INFUSION THERAPY: A

RETROSPECTIVE REVIEW, Maureen Geraghty, School Allied Medical Professionals

Dear Dr. Geraghty,

The Biomedical IRB APPROVED BY EXPEDITED REVIEW the above referenced research. The Board was able to provide expedited approval under 45 CFR $46.110(b)(1)$ because the research presents minimal risk to subjects and qualifies under the expedited review category(s) listed below.

\section{Date of IRB Approval: \\ Date of IRB Approval Expiration: \\ Expedited Review Category: \\ November 5, 2009 \\ November 5, 2010 \\ 5}

In addition; the research has been approved for a waiver of the consent process and for a waiver of HIPAA Research Authorization (entire research study).

If applicable, informed consent (and HIPAA research authorization) must be obtained from subjects or their legally authorized representatives and documented prior to research involvement. The IRB-approved consent form and process must be used. Changes in the research (e.g., recruitment procedures, advertisements, enrollment numbers, etc.) or informed consent process must be approved by the IRB before they are implemented (except where necessary to eliminate apparent immediate hazards to subjects).

This approval is valid for one year from the date of $\mathbb{R B}$ review when approval is granted or modifications are required. The approval will no longer be in effect on the date listed above as the IRB expiration date. A Continuing Review application must be approved within this interval to avoid expiration of IRB approval and cessation of all research activities. A final report must be provided to the IRB and all records relating to the research (including signed consent forms) must be retained and available for audit for at least 3 years after the research has ended.

It is the responsibility of all investigators and research staff to promptly report to the IRB any serious, unexpected and related adverse events and potential unanticipated problems involving risks to subjects or others.

This approval is issued under The Ohio State University's OHRP Federalwide Assurance $\# 00006378$.

All forms and procedures can be found on the ORRP website - www. orrp.osu.edu. Please feel free to contact the IRB staff contact listed above with any questions or concerns.

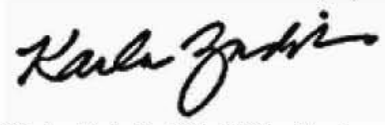

Karla Zadnik, OD, PhD, Chair

Biomedical Institutional Review Board 
APPENDIX B

Case Report Form 


\section{Case Report Form}

Code:

Age:

Gender:

Duration of Diabetes:

Age at Diagnosis:

\section{Pre-Insulin Pump Information}

Total Daily Insulin Dose:

Insulin Regimen:

Date:

Insulin/kg Body Weight:

Date:

\section{Post-Insulin Pump Information}

Total Daily Insulin Dose:

Insulin Regimen:

Date:

Insulin/kg Body Weight:

Date:

Number of Post-Education Classes Attended:

List of Post-Education Classes Attended:

Miscellaneous:
Complications:

Type of Insulin:

Type of Insulin Pump:

$\mathrm{HbA}_{1 \mathrm{c}}$ :

Date:

Weight:

Date:

$\mathrm{HbA}_{1 \mathrm{c}}$ :

Date:

Weight:

Date: 


\section{APPENDIX C}

\section{Additional Tables}

\begin{tabular}{|c|c|c|c|c|c|}
\hline Predictor & Slope & Standard Error & DF & t Value & Pr $>|\mathbf{t}|$ \\
\hline Age & -0.01102 & 0.009968 & 40 & -1.11 & 0.2757 \\
\hline Duration of Diabetes & -0.0098 & 0.01011 & 39 & -0.97 & 0.338 \\
\hline Age at Diagnosis & -0.00351 & 0.01097 & 39 & -0.32 & 0.7507 \\
\hline $\begin{array}{c}\text { Pre-Pump Average } \\
\text { Insulin }\end{array}$ & 0.004821 & 0.00769 & 40 & 0.63 & 0.5342 \\
\hline $\begin{array}{c}\text { Pre-Pump Insulin Per } \\
\text { Kilogram of Body } \\
\text { Weight }\end{array}$ & 0.1624 & 0.7732 & 40 & 0.21 & 0.8347 \\
\hline Pre-Pump Weight & 0.002332 & 0.008841 & 40 & 0.26 & 0.7933 \\
\hline
\end{tabular}

Table A.1: Univariate Analysis of Continuous Predictors 


\begin{tabular}{|c|c|c|c|c|c|c|c|}
\hline Variable & Level & $\mathbf{N}$ & $\begin{array}{c}\mathbf{H b A}_{1 \mathbf{c}} \\
\text { difference* }^{*}\end{array}$ & $\begin{array}{c}\text { Num } \\
\text { df }\end{array}$ & $\begin{array}{c}\text { Den } \\
\text { df }\end{array}$ & $\begin{array}{c}\mathbf{F} \\
\text { value }\end{array}$ & $\boldsymbol{P}$ \\
\hline \multirow[t]{3}{*}{ Type of insulin } & Apidra & 2 & $-0.45(1.2)$ & 2 & 39 & 0.02 & 0.981 \\
\hline & Humalog & 28 & $-0.55(0.9)$ & & & & \\
\hline & Novolog & 12 & $-0.58(0.68)$ & & & & \\
\hline \multirow{2}{*}{$\begin{array}{l}\text { Type of insulin } \\
\text { ( } 2 \text { categories) }\end{array}$} & Humalog & 28 & $-0.55(0.9)$ & 1 & 38 & 0.01 & 0.9221 \\
\hline & Novolog & 12 & $-0.58(0.68)$ & & & & \\
\hline \multirow[t]{2}{*}{ Gender } & Female & 24 & $-0.52(0.86)$ & 1 & 40 & 0.09 & 0.7683 \\
\hline & Male & 18 & $-0.59(0.82)$ & & & & \\
\hline \multirow[t]{3}{*}{ Pump } & Deltec Cozmo & 6 & $-0.72(1.13)$ & 2 & 39 & 1.2 & 0.3118 \\
\hline & Medtronic & 34 & $-0.47(0.78)$ & & & & \\
\hline & OmniPod & 2 & $-1.35(0.35)$ & & & & \\
\hline \multirow{2}{*}{$\begin{array}{l}\text { Pump ( } 2 \\
\text { categories) }\end{array}$} & Medtronic & 34 & $-0.47(0.78)$ & 1 & 40 & 1.53 & 0.2236 \\
\hline & Other & 8 & $-0.88(1.01)$ & & & & \\
\hline \multirow[t]{2}{*}{ Hypothyroid } & 0 & 36 & $-0.5(0.82)$ & 1 & 40 & 0.81 & 0.374 \\
\hline & 1 & 6 & $-0.83(0.92)$ & & & & \\
\hline \multirow[t]{2}{*}{ Hyperlipidemia } & 0 & 26 & $-0.61(0.75)$ & 1 & 40 & 0.37 & 0.5476 \\
\hline & 1 & 16 & $-0.45(0.96)$ & & & & \\
\hline \multirow[t]{2}{*}{ Hypertension } & 0 & 35 & $-0.52(0.79)$ & 1 & 40 & 0.22 & 0.6421 \\
\hline & 1 & 7 & $-0.69(1.1)$ & & & & \\
\hline \multirow[t]{2}{*}{ Neuropathy } & 0 & 24 & $-0.69(0.97)$ & 1 & 40 & 1.65 & 0.2063 \\
\hline & 1 & 18 & $-0.36(0.58)$ & & & & \\
\hline \multirow[t]{2}{*}{ Retinopathy } & 0 & 26 & $-0.46(0.88)$ & 1 & 40 & 0.84 & 0.3657 \\
\hline & 1 & 16 & $-0.7(0.75)$ & & & & \\
\hline \multirow{2}{*}{$\begin{array}{l}\text { Year of Pre-Pump } \\
\text { Education (2008- } \\
\text { 2009) }\end{array}$} & 0 & 32 & $-0.52(0.84)$ & 1 & 40 & 0.19 & 0.6686 \\
\hline & 1 & 10 & $-0.65(0.83)$ & & & & \\
\hline
\end{tabular}

*Data are presented as Mean (SD)

Table A.2: Univariate Analysis of Categorical Predictors 